\title{
Protein Hydration Dynamics in Aqueous Solution: A Comparison of Bovine Pancreatic Trypsin Inhibitor and Ubiquitin by Oxygen-17 Spin Relaxation Dispersion
}

\author{
Vladimir P. Denisov* and Bertil Halle
}

Condensed Matter Magnetic Resonance Group, Chemical Center, Lund University P.O. Box 124, S-22100 Lund Sweden

\begin{abstract}
Water oxygen-17 spin relaxation was used to study hydration and dynamics of the globular proteins bovine pancreatic trypsin inhibitor (BPTI) and ubiquitin in aqueous solution. The frequency dispersion of the longitudinal and transverse relaxation rates was measured over the Larmor frequency range 2.6 to $49 \mathrm{MHz}$ in the $\mathrm{pD}$ range 2 to 11 at $27^{\circ} \mathrm{C}$. While the protein-induced relaxation enhancement was similar for the two proteins at high frequencies, it was an order of magnitude smaller for ubiquitin than for BPTI at low frequencies. This difference was ascribed to the abscence, in ubiquitin, of highly ordered internal water molecules, which are known to be present in BPTI and in most other globular proteins. These observations demonstrate that the water relaxation dispersion in protein solutions is essentially due to a few structural water molecules buried within the protein matrix, but exchanging rapidly with the external water. The relaxation data indicate that the internal water molecules of BPTI exchange with bulk water on the time-scale $10^{-8}$ to $10^{-6}$ second thus lowering the recently reported upper bound on the residence time of these internal water molecules by four orders of magnitude, and implying that local unfolding occurs on the submicrosecond time-scale. The water molecules residing at the surface of the two proteins were found to be highly mobile, with an average rotational correlation time of approximately 20 picoseconds. For both proteins, the oxygen-17 relaxation depended only very weakly on $\mathrm{pD}$, showing that ionic residues do not perturb hydration water dynamics more than other surface residues. We believe that the present results resolve the long-standing controversy regarding the mechanism behind the spin relaxation dispersion of water nuclei in protein solutions, thus establishing oxygen-17 relaxation as a powerful tool for studies of structurally and functionally important water molecules in proteins and other biomolecules.
\end{abstract}

Keywords: protein hydration; internal water; nuclear magnetic resonance; bovine pancreatic trypsin inhibitor; ubiquitin

\section{Introduction}

The water-protein interaction has long been recognized as a major determinant of chain folding, conformational stability, and internal dynamics of globular proteins, and as an important modulator of the interactions that govern substrate binding,

Permanent address: V. P. Denisov, Department of Physics, Moscow State University, Moscow, 119899, Russia.

Abbreviations used: BPTI, bovine pancreatic trypsin inhibitor; NOE, nuclear Overhauser effect; QCC, quadrupole coupling constant. enzyme catalysis, and supramolecular recognition and assembly (Kuntz \& Kauzmann, 1974; Finney, 1979; Edsall \& McKenzie, 1983; Baker \& Hubbard, 1984; Rupley \& Careri, 1991). Despite a massive effort to quantify the water-protein interaction and its dynamic consequences, mainly by means of $X$-ray and neutron diffraction (Finney, 1979; Edsall \& McKenzie, 1983; Baker \& Hubbard, 1984; Kossiakoff, 1985; Rashin et al., 1986; Saenger, 1987; Thanki et al., 1988, 1991; Teeter, 1991; Sreenivasan \& Axelsen, 1992; Kuhn et al., 1992; Meyer, 1992), nuclear spin relaxation dispersion (Koenig, 1980; Halle et al., 1981; Piculell \& Halle, 1986; Schauer et al., 1988; Bryant, 1988; Hills et al., 1989; Kimmich et al., 1990; Koenig 
\& Brown, 1991; Hills, 1992; Belton, 1994), highresolution multi-dimensional NMR spectroscopy (Otting \& Wüthrich, 1989; Clore et al., 1990; Otting et al., 1991a; Forman-Kay et al., 1991; Clore \& Gronenborn, 1992; Xu et al., 1993; Grzesiek et al., 1994), and computer simulation (Teeter, 1991; van Gunsteren \& Mark, 1992; Daggett \& Levitt, 1993), a general consensus about all aspects of the waterprotein interaction has still not emerged.

To fully understand the structural and functional roles of protein-associated water molecules, the static structural view provided by high-resolution crystallography should be supplemented with dynamic information. In other words one needs to know, not only the spatial distribution, but also the residence times and local fluctuations of protein-associated water molecules. Although such dynamic information is contained in the nuclear spin relaxation dispersion of the water nuclei ${ }^{1} \mathrm{H},{ }^{2} \mathrm{H}$, and ${ }^{17} \mathrm{O}$, the interpretation of such data has proved to be non-trivial.

The ${ }^{1} \mathrm{H}$ dispersion is complicated by cross-relaxation between protein and water protons (Edzes \& Samulski, 1978; Koenig et al., 1978; Hills, 1992), and both ${ }^{1} \mathrm{H}$ and ${ }^{2} \mathrm{H}$ relaxation are affected by hydrogen exchange between water and protein (Picullel \& Halle, 1986; Hills et al., 1989; Hills, 1992; Denisov \& Halle, 1995). Even the ${ }^{17}$ Orelaxation dispersion, which does not suffer from these complications, cannot, by itself, provide a unique, model-independent picture of protein hydration. In particular, it does not appear possible, solely on the basis of relaxation dispersion data, to determine both the number of perturbed water molecules and the degree of this perturbation (relative to bulk water).

It has long been recognized that the observed relaxation dispersion from protein solutions can be produced by either a small number (typically, one to ten) of highly orientationally ordered water molecules or by several hundred weakly ordered water molecules. In connection with previous ${ }^{17} \mathrm{O}$ relaxation studies, two weighty arguments were advanced in favor of a relaxation dispersion induced by a weakly ordered hydration layer (Halle et al., 1981; Piculell \& Halle, 1986; Halle \& Piculell, 1986). First, the normalized relaxation dispersion step did not vary much among the half-dozen proteins examined, contrary to what would be expected if the dispersion was due to a small number of highly ordered water molecules in specific binding sites. Second, for a reasonable extent of hydration (one to two molecular layers), the dispersion data yielded an (average) order parameter of similar magnitude as found in amphiphile-water and other model systems. This interpretation required, however, that hundreds of water molecules at the protein surface have residence times longer than the rotational correlation time of the protein (typically, $10^{-8}$ second). This prediction has not been confirmed by subsequent computer simulation studies (Ahlström et al., 1988; Brunne et al., 1993), although these are subject to their own methodological limitations. Furthermore, high-resolution multidimensional ${ }^{1} \mathrm{HNMR}$ studies of several small proteins
(Otting \& Wüthrich, 1989; Clore et al., 1990; Clore \& Gronenborn, 1992; Xu et al., 1993) have so far detected only surface water molecules with residence times in the subnanosecond range. Finally, ${ }^{2} \mathrm{H}$ and ${ }^{17} \mathrm{O}$ spin relaxation studies of water at the interface of amphiphilic aggregates do not show the relaxation dispersion expected for long $\left(>10^{-8}\right.$ second) water residence times (Carlström \& Halle, 1989).

With the aim of resolving the interpretational ambiguity, we report here the results of an extensive ${ }^{17} \mathrm{O}$ relaxation dispersion study of the two proteins bovine pancreatic trypsin inhibitor (BPTI) and ubiquitin. Covering the Larmor frequency range 2.6 to $49 \mathrm{MHz}$, the present data constitute the first essentially complete ${ }^{17} \mathrm{O}$ relaxation dispersion reported for any system. Although the investigated proteins, with 58 and 76 residues, respectively, are both compactly folded and have similar surface properties (Kuhnetal., 1992), they differ in one important respect: BPTI has four internal water molecules (Deisenhofer \& Steigemann, 1975; Wlodawer et al., 1984, 1987a,b; Otting \& Wüthrich, 1989) while ubiquitin has none (Vijay-Kumar et al., 1987). We find that the ${ }^{17} \mathrm{O}$ relaxation dispersions from these proteins are radically different, strongly suggesting that the dispersion is due to internal water molecules. This conclusion is further supported by a quantitative analysis of the relaxation data, which also shows that the local unfolding of the dominant protein conformation required for exchange of these buried water molecules with the external water takes place on a submicrosecond time-scale. This result lowers the most recent (Otting et al., 1991b) upper bound for the residence time of internal water molecules in BPTI by four orders of magnitude.

With the interpretational ambiguity resolved, the ${ }^{17} \mathrm{O}$ relaxation method can now be used with some confidence to obtain detailed information about the dynamics and ordering of structurally and functionally important water molecules in various biomolecular systems.

In the accompanying paper (Denisov \& Halle, 1995), we report the ${ }^{2} \mathrm{H}$ relaxation dispersion from the same BPTI and ubiquitin solutions as studied here. In contrast to the ${ }^{17} \mathrm{O}$ dispersion reported here, the ${ }^{2} \mathrm{H}$ dispersion is strongly pD-dependent. By analyzing this $\mathrm{pD}$ dependence we are able, for the first time, to quantify the controversial contribution to the ${ }^{2} \mathrm{H}$ relaxation from labile protein hydrogen atoms exchanging with the water hydrogen atoms.

\section{Results and Discussion}

\section{Oxygen-17 spin relaxation of water in protein solutions}

In aqueous protein solutions the longitudinal $\left(R_{1}\right)$ and transverse $\left(R_{2}\right)$ spin relaxation rates of the quadrupolar ${ }^{17} \mathrm{O}$ nucleus in water are generally found to exceed the bulk water relaxation rate $\left(R_{\text {bulk }}\right)$. In contrast to the bulk water relaxation, the proteininduced excess relaxation exhibits a frequency 


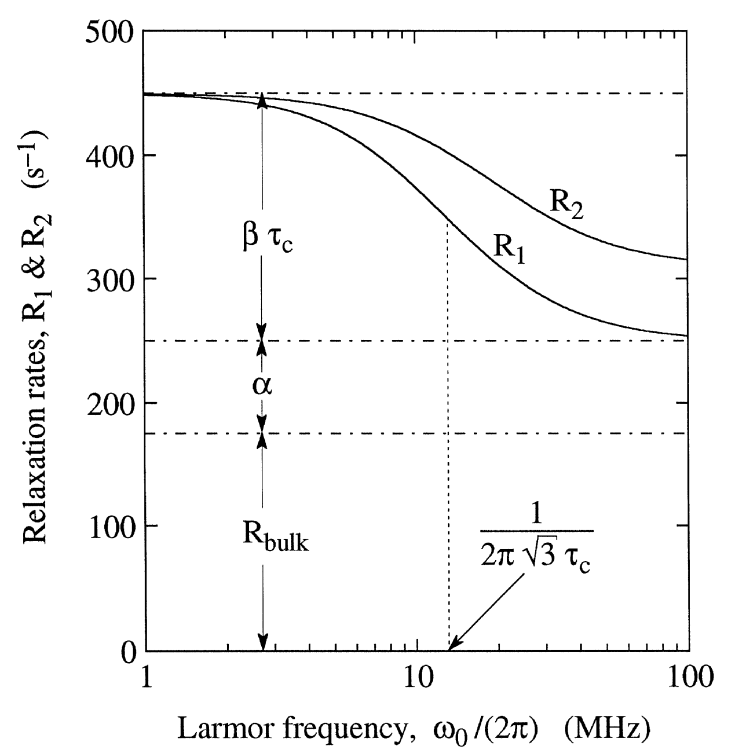

Figure 1. Theoretical relaxation dispersion of water ${ }^{17} \mathrm{O}$ nuclei in a protein solution, as predicted by equations (1) and (2) with the parameters $\alpha, \beta$, and $\tau_{\mathrm{c}}$ taken from Figure 2 and with $\gamma=0$.

dependence in the 0.1 to $100 \mathrm{MHz}$ range (depending on protein size) of Larmor frequencies. This relaxation dispersion directly demonstrates that at least some of the water molecules in the protein solution experience slow rotational motion with a correlation time (typically of order $10^{-8}$ second) inversely related to the characteristic frequency (inflection point) of the dispersion. Furthermore, a substantial relaxation excess remains well above the dispersion frequency (up to the highest experimentally accessible ${ }^{17} \mathrm{O}$ frequency of approximately $100 \mathrm{MHz}$ ), demonstrating that some of the water molecules also experience a protein-perturbed rotational motion on a subnanosecond time-scale.

The simplest conceivable expressions for the relaxation rates that are compatible with these general experimental observations and with the well-established theory of quadrupolar spin relaxation (Abragam, 1961; Halle \& Wennerström, 1981b) are:

$$
\begin{gathered}
R_{1}\left(\omega_{0}\right)=R_{\text {bulk }}+\alpha+\beta \tau_{c} F_{1}\left(\omega_{0} \tau_{c}\right), \\
R_{2}\left(\omega_{0}\right)=R_{\text {bulk }}+\alpha+\beta \tau_{c} F_{2}\left(\omega_{0} \tau_{c}\right)+\gamma,
\end{gathered}
$$

with the dispersion functions:

$$
\begin{gathered}
F_{1}(x)=\frac{0.2}{1+x^{2}}+\frac{0.8}{1+4 x^{2}} \\
F_{2}(x)=0.3+\frac{0.5}{1+x^{2}}+\frac{0.2}{1+4 x^{2}} .
\end{gathered}
$$

The significance of the parameters $\alpha, \beta$, and $\tau_{\mathrm{c}}$ is illustrated in Figure 1. The fourth parameter, $\gamma$, accounts for the frequency-independent contribution to $R_{2}$ from scalar relaxation of the first kind (Abragam, 1961), induced by exchange modulation of the electron-mediated coupling between the ${ }^{17} \mathrm{O}$ and ${ }^{2} \mathrm{H}$ nuclear spins in a water molecule (Meiboom, 1961; Halle \& Karlström, 1983).
The dispersion functions in equation (2) are strictly valid only if the slow rotational motion can be described by an exponentially decaying time correlation function, as is the case for rotational diffusion of an effectively spherical protein; a non-spherical protein shape tends to stretch out the dispersion over a broader frequency range. This effect can be accounted for by replacing equations (1) and (2) with the corresponding expressions for rotational diffusion of a symmetric top (Woessner, 1962). This more general description involves, besides the previous parameters, also the ratio $D_{\|} / D_{\perp}$ of the spinning and tumbling rotational diffusion coefficients $\left(\tau_{c}\right.$ is now defined as $1 /\left(6 D_{\perp}\right)$ ) and the angle $\theta_{\mathrm{I}}$ between the principal axis of the rotational diffusion tensor and the ${ }^{17} \mathrm{O}$ electric field gradient principal axis (normal to the plane of the water molecule) for all water molecules that contribute to the relaxation dispersion. As shown in Protein rotational diffusion, below, however, the hydrodynamic shapes of BPTI and ubiquitin are not sufficiently anisometric to produce significant deviations from the simple dispersion form of equations (1) and (2).

Since the observed relaxation rates represent averages over all water molecules that exchange rapidly with the bulk water, the interpretation of the parameters $\alpha$ and $\beta$ is highly model-dependent. Each of these parameters involves a product of the number of water molecules that are perturbed by the protein and a factor that measures the degree of this perturbation (relative to bulk water). On a molecular scale, a protein solution is a highly heterogeneous system where a water molecule samples many different local environments on the spin relaxation time-scale. If the exchange of water nuclei between these environments is fast compared to the difference of the corresponding intrinsic spin relaxation rates, we can express the observed relaxation rates as population weighted averages of the intrinsic rates:

$$
R_{\mathrm{k}}\left(\omega_{0}\right)=(1-f) R_{\text {bulk }}+f\left\langle R_{\mathrm{Pk}}\left(\omega_{0}\right)\right\rangle,(\mathrm{k}=1,2),
$$

where $\langle\ldots\rangle$ represents an average over the fraction $f$ of perturbed water molecules with intrinsic relaxation rates $R_{\mathrm{Pk}}\left(\omega_{0}\right)$. (The separation of the water molecules into a bulk phase and a perturbed phase is meaningful only if the spatial range of the perturbation is short.)

To bring equation (3) into the same form as equation (1), which is known to describe the experimental data, we explicitly separate the frequency-independent and frequency-dependent parts of the second term in equation (3), which refers to protein-associated (non-bulk) water:

$$
R_{\mathrm{k}}\left(\omega_{0}\right)=\left(1-\mathrm{F}_{\mathrm{S}}-f_{\mathrm{I}}\right) R_{\text {bulk }}+f_{\mathrm{S}}\left\langle R_{\mathrm{S}}\right\rangle+f_{\mathrm{I}}\left\langle R_{\mathrm{Ik}}\left(\omega_{0}\right)\right\rangle,
$$

where the choice of the subscripts I and $S$ anticipates our interpretation of these terms as arising, respectively, from long-lived internal water molecules (I) and mobile water molecules residing at the protein surface (S). It should be noted, however, that 
the form of equation (4) does not force us to adopt this interpretation. We assume that the intrinsic relaxation rate $R_{\mathrm{S}}$ is independent of frequency in the investigated range and, therefore, contributes equally to $R_{1}$ and $R_{2}$. In practice, this means that the effective correlation time associated with $R_{\mathrm{S}}$ is significantly shorter than one nanosecond. Furthermore, we identify the correlation time $\tau_{\mathrm{c}}$ associated with $\left\langle R_{\mathrm{Ik}}\left(\omega_{0}\right)\right\rangle$ with the (second-rank) rotational correlation time $\tau_{\mathrm{R}}$ of the (effectively spherical) protein molecule. If all water molecules that contribute to this term have residence times much longer then $\tau_{R}$, we can write:

$$
\left\langle R_{\mathrm{Ik}}\left(\omega_{0}\right)\right\rangle=\left\langle R_{\mathrm{I}}\right\rangle F_{\mathrm{k}}\left(\omega_{0} \tau_{\mathrm{R}}\right),
$$

with $R_{\mathrm{I}}=R_{\mathrm{Ik}}(0)$. Comparing equation (1) with equations (4) and (5), we can now express the experimentally accessible parameters $\alpha$ and $\beta$ as:

$$
\begin{gathered}
\alpha=f_{\mathrm{S}}\left\langle R_{\mathrm{S}}\right\rangle-\left(f_{\mathrm{S}}+f_{\mathrm{I}}\right) R_{\text {bulk }}, \\
\beta=f_{\mathrm{I}}\left\langle R_{\mathrm{I}}\right\rangle / \tau_{\mathrm{R}} .
\end{gathered}
$$

Next we consider the nature of the intrinsic (zero-frequency) relaxation rates $R_{\mathrm{S}}$ and $R_{\mathrm{I}}$. A general theoretical framework for spin relaxation of water nuclei in heterogeneous systems with locally anisotropic environments has been developed (Halle \& Wennerström, 1981a). (This essentially modelindependent description is equally applicable to the relaxation of ${ }^{13} \mathrm{C}$ or ${ }^{15} \mathrm{~N}$ nuclei in the protein and, in this context, it has been popularized by Lipari \& Szabo (1982)). The usefulness of this theoretical framework derives from its ability to rigorously describe the effect of internal motions (in the present context, restricted reorientation of water molecules with respect to the protein molecule) without the need to model these motions in detail. This is accomplished by introducing a generalized order parameter A (Halle \& Wennerström, 1981a), sometimes referred to as the residual anisotropy, which is essentially a measure of the orientational ordering of water molecules relative to the protein. If the internal motions are much faster than the global motions, the intrinsic zero-frequency relaxation rate can be decomposed into two independent terms of the form (Halle \&Wennerström, 1981a):

$$
R_{\mathrm{I}, \mathrm{S}} \propto\left(1+\frac{1}{3} \eta^{2}-A^{2}\right) \tau_{\text {fast }}+A^{2} \tau_{\text {slow }},
$$

where $\eta$ is the asymmetry parameter of the electric field gradient tensor, $\tau_{\text {fast }}$ is the effective correlation time for the internal motions, and $\tau_{\text {slow }}=$ $1 /\left(1 / \tau_{\text {res }}+1 / \tau_{\mathrm{R}}\right)$, with $\tau_{\text {res }}$ the mean residence time of the protein-associated water molecules and $\tau_{\mathrm{R}}$ the rotational correlation time of the protein molecule. Typically, $\tau_{\text {fast }} \approx 10 \mathrm{ps}$ and $\tau_{\mathrm{R}} \approx 10 \mathrm{~ns}$. For highly ordered $(A \approx 1)$ water molecules the intrinsic relaxation rate is completely dominated by the second term in equation (7), unless $\tau_{\text {res }} \ll \tau_{R}$; even for very weakly ordered $(A \ll 1)$ water molecules this term can make a substantial contribution provided that the residence time is long $\left(\tau_{\text {res }} \geqslant \tau_{\mathrm{R}}\right)$.

The BPTI solutions investigated here contain 2600 water molecules per protein molecule. Of these, approximately 250 are in contact with the protein surface (Levitt \& Sharon, 1988), while four are buried inside the protein. If the three terms of equation (4) are associated with these three classes of water molecules, we thus have $f_{1} \ll f_{\mathrm{s}} \ll 1$. If the few internal water molecules are to contribute significantly to the relaxation, they must be highly ordered $(A \approx 1)$ and long-lived $\left(\tau_{\text {res }} \geqslant \tau_{R}\right)$, as indeed expected for such water molecules. The second term in equation (7) then completely dominates $R_{\mathrm{I}}$, which can be written as $R_{\mathrm{I}}=\left(12 \pi^{2} / 125\right) A_{I}^{2} \chi_{\mathrm{I}}^{2} \tau_{\mathrm{R}}$ (Halle \& Wennerström, $1981 a)$, and the experimental parameters in equation (6) become:

$$
\begin{gathered}
\alpha=f_{\mathrm{S}}\left(\left\langle R_{\mathrm{S}}\right\rangle-R_{\text {bulk }}\right), \\
\beta=\frac{12 \pi^{2}}{125} f_{\mathrm{I}}\left\langle A_{\mathrm{I}}^{2} \chi_{\mathrm{I}}^{2}\right\rangle,
\end{gathered}
$$

with $\chi_{\mathrm{I}}$ the quadrupole coupling constant of the ${ }^{17} \mathrm{O}$ nucleus in an internal water molecule.

An alternative interpretation of the parameter $\beta$ is possible (Halle et al., 1981; Piculell \& Halle, 1986; Halle \& Piculell, 1986). If all protein-associated water molecules, including any rapidly exchanging internal water molecules are weakly ordered $(A \ll 1)$, then $\beta$ is essentially due to the more numerous surface water molecules. This requires, however, that all these surface water molecules are long-lived $\left(\tau_{\text {res }} \geqslant \tau_{\mathrm{R}}\right)$; otherwise the relaxation dispersion cannot be accounted for. In this picture, the parameter $\beta$, given by equation ( $8 b$ ) with the I subscripts replaced by $S$, thus reflects the slow component (second term of equation (7)) of the reorientational motion (with respect to a laboratory-fixed frame) of the same surface water molecules whose fast internal motions (first term of equation (7)) is responsible for the parameter $\alpha$ in equation (8a). In the following, we present experimental data that allow us to discriminate between these alternative interpretations.

\section{Relaxation dispersion in BPTI and ubiquitin solutions}

The ${ }^{17} \mathrm{O}$ relaxation dispersions in solutions of BPTI and ubiquitin at $\mathrm{pD} 3.4$ are shown in Figures 2 and 3. The parameters $\alpha, \beta, \gamma$ and $\tau_{\mathrm{c}}$ in equations (1) and (2) were determined from non-linear least-squares fits to these data. In the case of ubiquitin, where the ${ }^{17} \mathrm{O}$ dispersion is very weak, the correlation time $\tau_{c}$ was obtained from the much stronger ${ }^{2} \mathrm{H}$ dispersion measured on the same sample (Denisov \& Halle, 1995). The curves shown in Figures 2 and 3 resulted from a simultaneous fit to the $R_{1}$ and $R_{2}$ data. Inclusion of $R_{2}$ data in the fit does not significantly alter the parameter values obtained from only the $R_{1}$ data. However, the $R_{2}$ data exclude possible systematic errors in the determination of the low-frequency $R_{1}$ plateau (and, hence, $\beta$ ). The transverse relaxation rate $R_{2}$ is affected, via the first term in equation ( $2 b)$, by slow motions, whereas the longitudinal relaxation rate $R_{1}$ is unaffected by motions on time-scales much longer than $1 / \omega_{0}$. Although our relaxation data only extend down to 


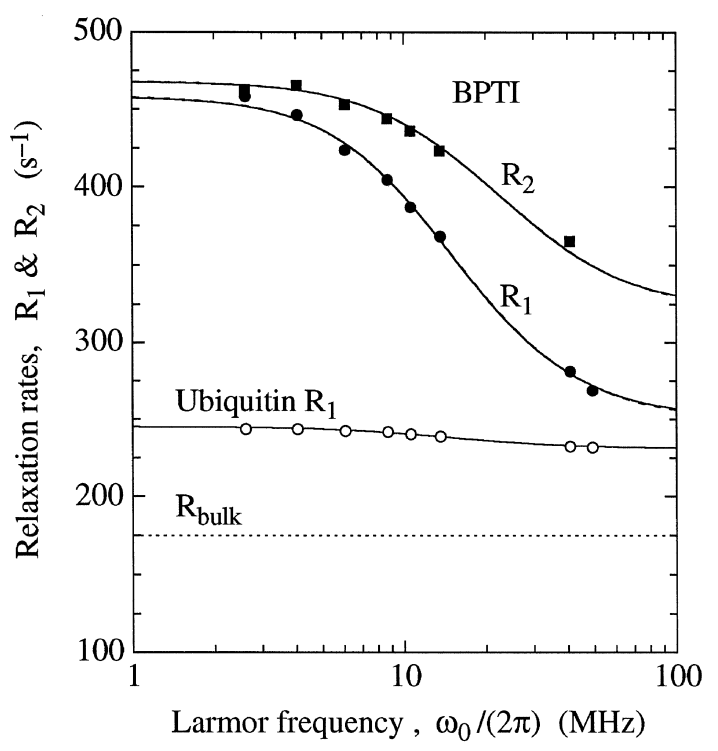

Figure 2. Water ${ }^{17} \mathrm{O}$ relaxation dispersion in a BPTI solution $\left(10.4 \%(\mathrm{w} / \mathrm{w}), \mathrm{pD} 3.40,27^{\circ} \mathrm{C}\right)$. The continuous curves resulted from a fit of the parameters $\alpha, \beta, \gamma$ and $\tau_{\mathrm{c}}$ in equations (1) and (2) to the 15 data points. The estimated error bars are the same size as the data symbols. For comparison, the ${ }^{17} \mathrm{O} R_{1}$ dispersion in a ubiquitin solution (from Figure 3) is also shown. The barely visible broken curves resulted from a fit to the BPTI data taking the non-spherical shape of the protein into account (see Results and Discussion, Protein rotational diffusion).

2.6 $\mathrm{MHz}$, we can thus be confident that the observed levelling off of $R_{1}$ at low frequencies defines the zero-frequency plateau, because only on this plateau is $R_{1}=R_{2}$. With only $R_{1}$ data available, one cannot exclude the possibility of a further dispersion step at

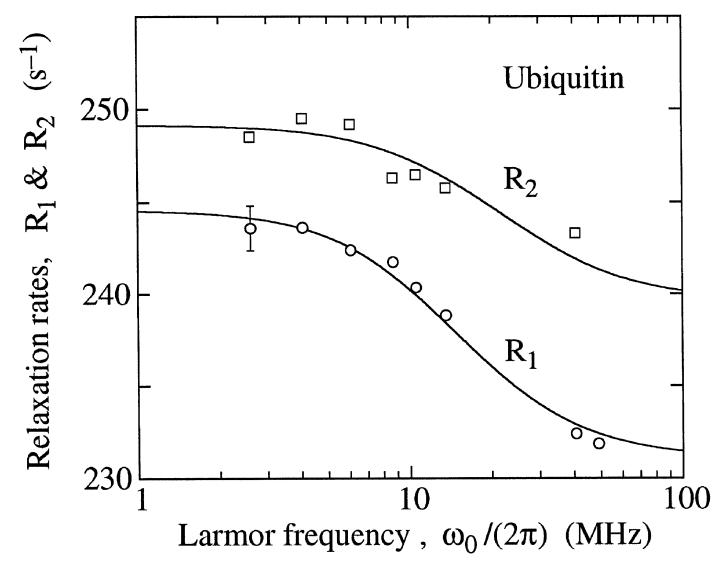

Figure 3. Water ${ }^{17} \mathrm{O}$ relaxation dispersion in a ubiquitin solution $\left(10.2 \%(\mathrm{w} / \mathrm{w}), \mathrm{pD} 3.35,27^{\circ} \mathrm{C}\right)$. Note the difference in scale from Figure 2. The continuous curves resulted from a fit of the parameters $\alpha, \beta$, and $\gamma$ in equation (1) to the 15 data points, with the correlation time $\tau_{\mathrm{c}}$ taken from the ${ }^{2} \mathrm{H}$ dispersion (Denisov \& Halle, 1995). The estimated experimental uncertainty is $\pm 0.5 \%$ for all data points (see error bar).

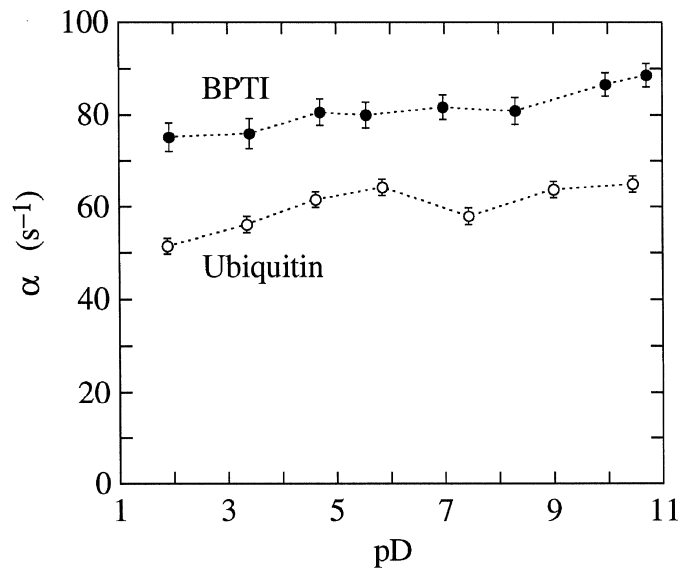

Figure 4. $\mathrm{pD}$ dependence of the high-frequency dispersion parameter $\alpha$, derived from the ${ }^{17} \mathrm{O}$ relaxation dispersion in BPTI and ubiquitin solutions.

lower frequencies which would affect the interpretation of $\beta$. The small difference $\gamma=R_{2}(0)-R_{1}(0)$ represents a frequency-independent contribution to $R_{2}$ from scalar relaxation (see Oxygen-17 spin relaxation of water in protein solutions, above). The $\mathrm{pD}$ dependence of $\gamma$ is qualitatively similar to that of scalar ${ }^{17} \mathrm{O}$ relaxation in bulk ${ }^{2} \mathrm{H}_{2} \mathrm{O}$ (Halle \& Karlström, 1983). At the lowest and highest investigated $\mathrm{pD}$ values, deuteron exchange among water molecules should be sufficiently fast that the scalar relaxation contribution to $R_{2}$ is negligible. For consistency, however, the $\gamma$ parameter was included in the fits at all $\mathrm{pD}$ values. If we postulate that $\gamma=0$ for the $\mathrm{pD} 3.4$ data in Figure 2, the remaining parameters $\alpha, \beta$ and $\tau_{\mathrm{c}}$ are changed by 2,3 , and $4 \%$, respectively.

The principal result of the present work is apparent from Figure 2, showing that a protein that is known to be free from internal water yields only a tiny relaxation dispersion. Due to the high accuracy of our ${ }^{17} \mathrm{O}$ relaxation data, however, even this small relaxation step can be clearly established (see Figure 3). The quantitative interpretation of the dispersion amplitudes for BPTI and ubiquitin is deferred until Internal water, below.

\section{$\mathrm{pD}$ dependence of $\alpha$ and $\beta$}

Figures 4 and 5 show the variation with $\mathrm{pD}$ of $\alpha$ and $\beta$, derived from ${ }^{17} \mathrm{O}$ relaxation dispersions (like those shown in Figures 2 and 3) in solutions of BPTI and ubiquitin of different $\mathrm{pD}$ values. In the investigated $\mathrm{pD}$ range the net charge of the BPTI molecule varies from +11 to -1 , while the number of charged residues increases from 11 at $\mathrm{pD} 2$ to 16 or 17 at $\mathrm{pD}>5$. For ubiquitin, the net charge varies from +13 to approximately -3 and the number of charged residues from 13 at $\mathrm{pD} 2$ to approximately 24 at $\mathrm{pD}>6$. Evidently the water-protein interaction, i.e. the number of perturbed water molecules and their orientational order and reorientational rate, does not depend crucially on the protonation state of 


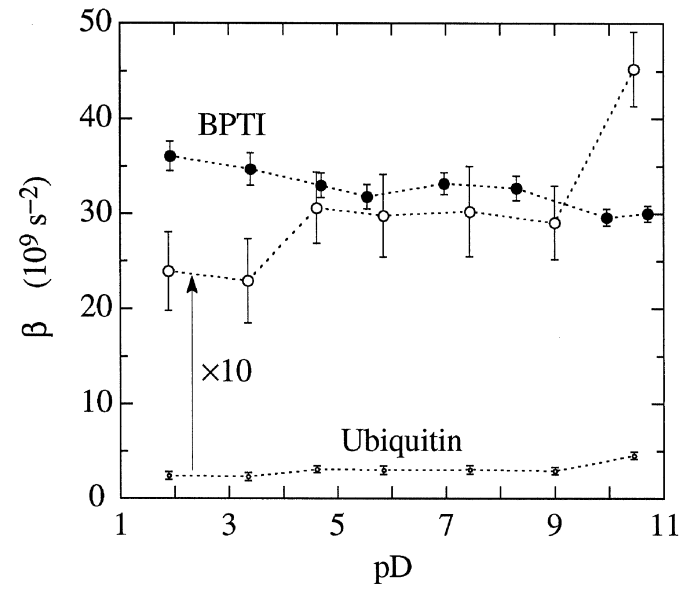

Figure 5. $\mathrm{pD}$ dependence of the low-frequency dispersion parameter $\beta$, derived from the ${ }^{17} \mathrm{O}$ relaxation dispersion in BPTI and ubiquitin solutions.

the acidic amino acid side-chains. For BPTI, the minor variations in $\alpha$ and $\beta$ seen below $\mathrm{pD} 4$ and above $\mathrm{pD} 9$ may reflect the disruption of the salt bridge between the $\mathrm{C}$ and $\mathrm{N}$ terminii and the consequent enhancement of conformational fluctuations (Brown et al., 1978).

\section{Protein rotational diffusion}

Figure 6 shows the variation with $\mathrm{pD}$ of the correlation time $\tau_{c}$, derived from the ${ }^{17} \mathrm{O}$ or, for ubiquitin, the ${ }^{2} \mathrm{H}$ relaxation dispersion fits. Our values at $27^{\circ} \mathrm{C}, \tau_{\mathrm{c}}=7.1( \pm 0.3) \mathrm{ns}$ for $19 \mathrm{mM}$ BPTI at pD 4.7 and $\tau_{\mathrm{c}}=7.8( \pm 0.3) \mathrm{ns}$ for $14 \mathrm{mM}$ ubiquitin at pD 4.6, may be compared with the values (scaled to our temperature and solvent viscosity assuming $\tau_{\mathrm{c}} \propto$ $\eta / T): \tau_{\mathrm{c}}=3.1( \pm 0.8) \mathrm{ns}$ for $5 \mathrm{mM}$ BPTI at $\mathrm{pH} 4.6$ (Szyperski et al., 1993) and $\tau_{\mathrm{c}}=4.3 \mathrm{~ns}$ for $2 \mathrm{mM}$ ubiquitin at $\mathrm{pH} 5.0$ (Schneider et al., 1992), both obtained from ${ }^{15} \mathrm{~N}$ relaxation, and $\tau_{\mathrm{c}}=5.5 \mathrm{~ns}$ for $25 \mathrm{mM}$ BPTI at pD 4.5, obtained from ${ }^{13} \mathrm{C}$ relaxation

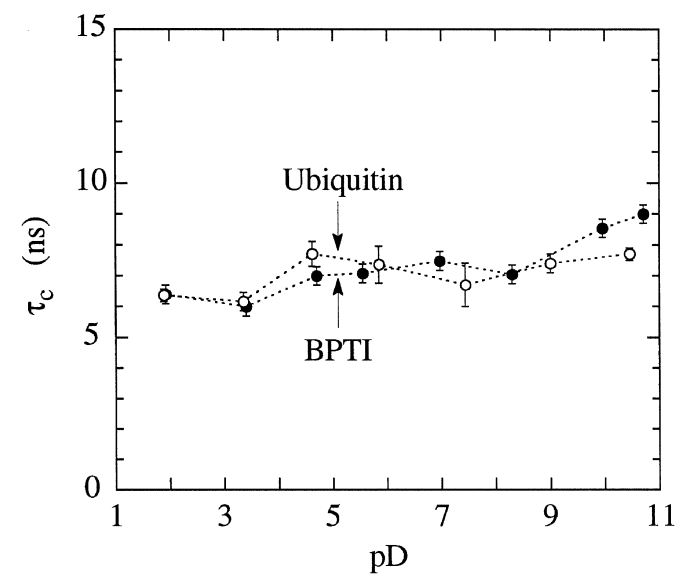

Figure 6. $\mathrm{pD}$ dependence of the correlation time $\tau_{\mathrm{c}}$, derived from the ${ }^{17} \mathrm{O}$ (BPTI) or ${ }^{2} \mathrm{H}$ (ubiquitin) relaxation dispersions in BPTI and ubiquitin solutions.
(Richarz et al., 1980). We identify $\tau_{\mathrm{c}}$ with the rotational correlation time $\tau_{\mathrm{R}}$ of the protein and ascribe the concentration-dependent increase of $\tau_{R}$ to proteinprotein interactions. The mean surface-to-surface separation between adjacent protein molecules is 20 to $25 \AA$ in our solutions. The weak pD dependence seen in Figure 6 may reflect variations in the electrostatic component of the protein-protein interaction, as well as minor conformational changes accompanying $\mathrm{pD}$-induced disruption of salt bridges.

As noted in Oxygen-17 spin relaxation of water in protein solutions, above, the dispersion functions in equation (2) are strictly valid only if the protein reorients as a spherical top. Although the ${ }^{17} \mathrm{O}$ relaxation data in Figures 2 and 3 are apparently well described by equations (1) and (2), it is conceivable that the parameters $\alpha, \beta$, and $\tau_{\mathrm{c}}$ obtained from the fits are affected by the non-spherical protein shape. To assess this potential source of systematic error we analyzed the data in terms of the generalization of equations (1) and (2) to the case of rotational diffusion of a symmetric top (Woessner, 1962). The angle $\theta_{\mathrm{I}}$ between the ${ }^{17} \mathrm{O}$ electric field gradient principal axis and the principal axis of the rotational diffusion tensor must then be specified for each of the internal water molecules which contribute to the BPTI dispersion (see Internal water, below). The hydrodynamic shape of the BPTI molecule can be approximated as a prolate spheroid of axial ratio 1.75, corresponding to $D_{\|} / D_{\perp}=1.61$ (Woessner, 1962). (Ubiquitin is less anisometric with an axial ratio of approximately 1.2, excluding the flexible chain segment at the $C$ terminus.) Using the known $\theta_{\mathrm{I}}$ values, given in Table 1 , and $D_{\|} / D_{\perp}=1.61$, we find that the fit to the BPTI data is virtually indistinguishable from the spherical-top fit (see the broken and continuous curves in Figure 2). The parameters $\alpha$ and $\beta$ from the two fits agree to within $2 \%$.

\section{Surface water}

The high-frequency parameter $\alpha$, shown in Figure 4 , depends on the number of perturbed water molecules at the protein surface as well as on the rotational dynamics of these water molecules. Expressing the surface water fraction as $f_{\mathrm{S}}=N_{\mathrm{S}} M_{\mathrm{W}} w /\left[M_{\mathrm{P}}(1-w)\right]$, we obtain from equation (8a):

$$
N_{\mathrm{S}}\left(\frac{\left\langle R_{\mathrm{S}}\right\rangle}{R_{\text {bulk }}}-1\right)=\frac{\alpha M_{\mathrm{P}}(1-w)}{R_{\mathrm{bulk}} M_{\mathrm{W}} w}
$$

with $N_{S}$ the number of perturbed surface water molecules per protein molecule, $w$ the protein mass fraction, and $M_{\mathrm{P}}$ and $M_{\mathrm{W}}$ the molar mass of protein and water (see Materials and Methods, Protein solutions). Since the protein surface is not expected to affect the ${ }^{17} \mathrm{O}$ quadrupole coupling constant much (Halle \& Wennerström, 1981a; Cummins et al., 1985), the ratio $\left\langle R_{\mathrm{S}}\right\rangle / R_{\text {bulk }}$ can be interpreted as the ratio $\tau_{S} / \tau_{\text {bulk }}$ of the (average) effective rotational correlation time for surface water 
Table 1

\begin{tabular}{|c|c|c|c|c|c|c|}
\hline \multicolumn{7}{|c|}{ Hydrogen bonds involving completely or partly buried water molecules in BPTI and ubiquitin } \\
\hline Water & Partner & $R_{\mathrm{OX}}(\AA)$ & $R_{\mathrm{HX}}(\AA)$ & $\theta_{\mathrm{OHX}}$ (deg.) & $\theta_{\mathrm{I}}(\mathrm{deg}.) \dagger$ & $\left\langle\Delta r^{2}\right\rangle^{1 / 2}(\AA) \ddagger$ \\
\hline \multirow[t]{4}{*}{ 5PTI-W122 } & Thr11 CO & 2.76 & 1.77 & 175 & 64 & 0.42 \\
\hline & Cys38 CO & 2.77 & 2.03 & 131 & & \\
\hline & Cys14 NH & 3.12 & 2.18 & 160 & & \\
\hline & Cys38 NH & 3.19 & 2.22 & 162 & & \\
\hline \multirow{4}{*}{ 5PTI-W113 } & W112 & 2.64 & 1.66 & 168 & 82 & 0.40 \\
\hline & Tyr10 CO & 2.88 & 1.93 & 176 & & \\
\hline & Asn $44 \mathrm{NH}_{2}$ & 2.90 & 1.89 & 169 & & \\
\hline & Lys41 NH & 3.05 & 2.06 & 165 & & \\
\hline \multirow[t]{4}{*}{ 5PTI-W112 } & W113 & 2.64 & 1.66 & 168 & 104 & 0.48 \\
\hline & Asn 43 CO & 2.77 & 1.84 & 163 & & \\
\hline & W111 & 2.89 & 2.03 & 153 & & \\
\hline & Tyr10 NH & 2.92 & 2.01 & 151 & & \\
\hline \multirow[t]{3}{*}{ 5PTI-W111 } & Glu7 $\mathrm{CO}_{2}$ & 2.60 & 1.74 & 147 & 95 & 0.65 \\
\hline & Pro8 CO & 2.69 & 1.88 & 142 & & \\
\hline & W112 & 2.89 & 2.03 & 153 & & \\
\hline \multirow{3}{*}{ 1UBQ-W28 } & Leu50 CO & 2.76 & & & & 0.33 \\
\hline & Leu43 NH & 2.91 & & & & \\
\hline & Lys27 $\mathrm{NH}_{3}$ & 3.36 & & & & \\
\hline
\end{tabular}

Data were obtained from files 5PTI and 1UBQ in the Protein Data Bank.

† Angle between the principal axes of the ${ }^{17} \mathrm{O}$ electric field gradient and protein rotational diffusion tensors, the latter being parallel to the line connecting the $\mathrm{C}^{\alpha}$ atom of Gly36 with the $\mathrm{C}^{\beta}$ atom of Tyr23 in BPTI.

$\ddagger$ Root-mean-square positional fluctuation of water oxygen, calculated from the crystallographic temperature factor $B$ as $\left\langle\Delta r^{2}\right\rangle^{1 / 2}=\left(3 B / 8 \pi^{2}\right)^{1 / 2}$.

molecules to the rotational correlation time of bulk water (approximately 3 ps in ${ }^{2} \mathrm{H}_{2} \mathrm{O}$ at $27^{\circ} \mathrm{C}$ ).

Figure 7 shows the quantity $N_{\mathrm{S}}\left(\left\langle R_{\mathrm{s}}\right\rangle / R_{\text {bulk }}-1\right)$ as a function of $\mathrm{pD}$ for BPTI and ubiquitin. Although we cannot rigorously separate the two factors in this composite quantity, it is instructive to estimate the dynamic perturbation $\tau_{S} / \tau_{\text {bulk }}$ with a reasonable value for $N_{s}$. According to a molecular dynamics simulation of BPTI, 231 water molecules are either within $3.2 \AA$ of a polar protein atom $(\mathrm{O}$ or $\mathrm{N})$ or within $4.5 \AA$ of a non-polar protein atom (Levitt \& Sharon, 1988). With $N_{S}=231$ we obtain from the data in Figure $7 \tau_{s} / \tau_{\text {bulk }}=6.2$ for BPTI (at $\mathrm{pD} 4.7$ ). Assuming that $N_{\mathrm{s}}$ scales as $M_{\mathrm{P}}^{2 / 3}$ we obtain, in the same way, $\tau_{\mathrm{s}} / \tau_{\text {bulk }}=5.5$ for ubiquitin (at $\mathrm{pD} 4.6$ ).

Since hydrogen bond disruption should be rate

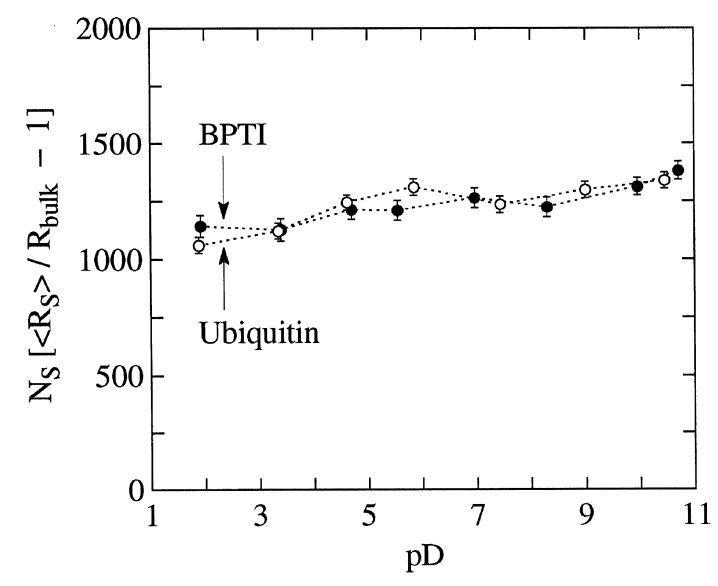

Figure 7. $\mathrm{pD}$ dependence of the composite quantity $N_{\mathrm{S}}\left[\left\langle R_{\mathrm{S}}\right\rangle / R_{\text {bulk }}-1\right]$, obtained from the high-frequency dispersion parameter $\alpha$ in Figure 4 . limiting for rotation as well as for translation of water molecules, these processes should take place on the same time-scale. (This is indeed the case in bulk water, where a water molecule on average rotates through one radian in the same time as it translates one diameter.) The ratio $\tau_{\varsigma} / \tau_{\text {bulk }}$ should therefore not differ much from the corresponding mean residence time ratio $\tau_{\mathrm{S}}^{\text {res }} / \tau_{\text {bulk }}^{\text {res }}$. The latter quantity was calculated in a recent simulation of BPTI at $4^{\circ} \mathrm{C}$ (Brunne et al., 1993); an average over all surface water molecules gave $\tau_{\mathrm{s}}^{\text {res }} / \tau_{\text {bulk }}^{\text {res }} \approx 3$. Bearing in mind that our estimate of $N_{S}$ is somewhat arbitrary, and that the protein-water pair potentials used in simulations are of uncertain quality (Smith \& van Gunsteren, 1994), the agreement is reassuring.

The X-ray and neutron structure of crystal form II of BPTI includes 59 water molecules, besides the four internal ones. About 20 of these reside at fully occupied sites and a few make the same hydrogen bonds in all three crystal forms (Wlodawer et al., 1987a). In the recent high-resolution ${ }^{1} \mathrm{H}$ NMR study of BPTI in solution (Otting \& Wüthrich, 1989; Otting et al., 1991a), NOEs from some 20 to 30 surface water molecules were observed. Among the conserved external waters in the crystal, only W129 and W143 could be observed in solution. All surface water molecules seen in the NMR study, including W129 and W143, appeared to have residence times shorter than 0.5 nanosecond $\left(\right.$ at $\left.4^{\circ} \mathrm{C}\right)$. The deduction of a residence time from the intensity of a cross-relaxation peak is somewhat model-dependent; in particular, neglect of internal mobility can lead to a substantial underestimate of $\tau_{\text {res }}$. Due to the qualitatively different effect of internal motion on the intermolecular ${ }^{1} \mathrm{H}$ cross-relaxation between water and protein protons and on the intramolecular ${ }^{17} \mathrm{O}$ relaxation of water, results from the two methods are 
not directly comparable. Although both ${ }^{1} \mathrm{H}$ and ${ }^{17} \mathrm{O}$ results are consistent with a short-lived (subnanosecond) surface hydration layer, neither experiment can rule out the existence of a small number of long-lived (>one nanosecond) surface water molecules, provided that they are weakly ordered $(A \ll 1)$. This possibility seems rather unlikely, however, since it is the well-ordered water molecules that are expected to have long residence times.

Since the quantity shown in Figure 7 represents an average over some 250 water molecules, it is not surprising that titration of the few carboxyl groups (5 in BPTI and 12 in ubiquitin) in the $\mathrm{pD}$ range 2 to 6 has little effect. The absence of a strong $\mathrm{pD}$ dependence in Figure 7 is also consistent with the simulation result that water molecules near charged residues do not have longer residence times than other surface water molecules (Brunne et al., 1993).

Although consistent with high-resolution ${ }^{1} \mathrm{H}$ NMR and molecular dynamics simulations, our results for the dynamics of surface water are clearly at variance with the picture emerging from the dielectric relaxation studies. For myoglobin it was concluded that half of the (several hundred) surface water molecules have $\tau_{\mathrm{S}} / \tau_{\text {bulk }} \approx 5$ (in agreement with our results), while the other half have $\tau_{\mathrm{s}} / \tau_{\text {bulk }} \approx 1200$ (Pethig, 1992). More recently, dielectric relaxation data from ten globular proteins were interpreted in terms of 50 to 250 surface water molecules per protein with an average $\tau_{\mathrm{S}} / \tau_{\text {bulk }}$ value in the range 160 to 325 (Miura et al., 1994).

\section{Internal water}

Finally we consider the parameter $\beta$ (see Figure 5), which is proportional to either the small number $\left(N_{\mathrm{I}}\right)$ of highly ordered internal water molecules or the much larger number $\left(N_{\mathrm{S}}\right)$ of weakly ordered surface water molecules, and to the square of the generalized order parameter $\left(A_{\mathrm{I}}\right.$ or $\left.A_{\mathrm{S}}\right)$. To discriminate between these alternative interpretations, it is helpful to focus on the ratio $\beta / \alpha$.

According to equations (8), if $\beta$ is due to surface water molecules, then:

$$
\frac{\beta}{\alpha}=\frac{12 \pi^{2}}{125} \frac{\left\langle A_{\mathrm{S}}^{2} \chi_{\mathrm{S}}^{2}\right\rangle}{\left\langle R_{\mathrm{S}}\right\rangle-R_{\mathrm{bulk}}} .
$$

Since both $\left\langle A_{\mathrm{S}}^{2} \chi_{\mathrm{S}}^{2}\right\rangle$ and $\left\langle R_{\mathrm{S}}\right\rangle$ are averaged over a large number $\left(N_{\mathrm{S}} \approx 250\right)$ of surface water molecules, the ratio $\beta / \alpha$ should not vary much among different globular proteins. In particular, the structurally similar proteins BPTI and ubiquitin should yield nearly the same value for $\beta / \alpha$ if $\beta$ is due to surface water molecules. As seen from Figure 8 , however, $\beta / \alpha$ is an order of magnitude larger for BPTI than for ubiquitin.

If, on the other hand, $\beta$ is due to internal water molecules, then equation (8) yields:

$$
\frac{\beta}{\alpha}=\frac{12 \pi^{2}}{125} \frac{\left\langle A_{\mathrm{I}}^{2} \chi_{\mathrm{I}}^{2}\right\rangle}{\left\langle R_{\mathrm{S}}\right\rangle-R_{\text {bulk }}} \frac{N_{\mathrm{I}}}{N_{\mathrm{S}}} \text {. }
$$

Since the number $\left(N_{\mathrm{I}}\right)$ of internal water molecules

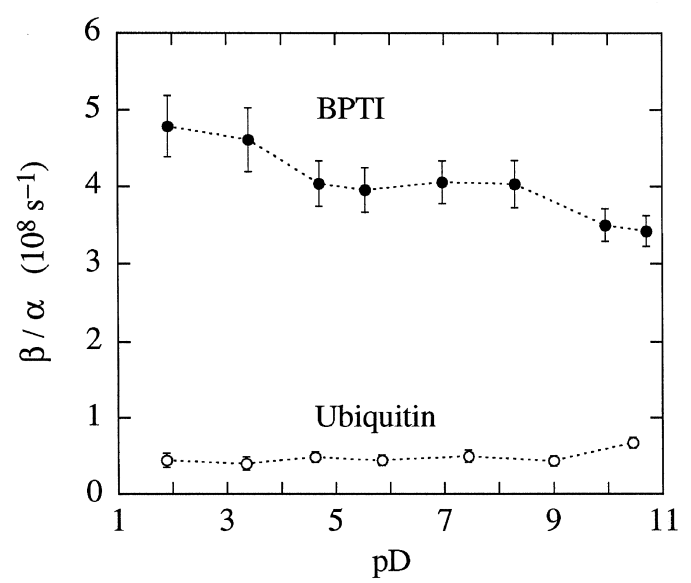

Figure 8. $\mathrm{pD}$ dependence of the ratio $\beta / \alpha$ of the dispersion parameters, derived from the ${ }^{17} \mathrm{O}$ relaxation dispersion in BPTI and ubiquitin solutions. The large values for BPTI are due to internal water molecules.

shows large (relative) variations (not directly correlated with $N_{\mathrm{S}}$ or surface area) among different proteins (Finney, 1979; Edsall \& McKenzie, 1983; Baker \& Hubbard, 1984; Rashin et al., 1986; Meyer, 1992), we expect a correspondingly large variation of the ratio $\beta / \alpha$. In particular, $\beta / \alpha$ should be much larger for BPTI, which contains four buried water molecules in all three investigated crystal forms (Deisenhofer \& Steigemann, 1975; Wlodawer et al., 1984, 1987a,b) as well as in solution (Otting \& Wüthrich, 1989; Otting et al., 1991a), than for ubiquitin, the crystal structure of which does not reveal any internal water molecules (Vijay-Kumar et al., 1987). In the light of this structural information, the data of Figure 8 strongly suggest that the observed ${ }^{17} \mathrm{O}$ relaxation dispersion is due to internal water molecules. In fact, this is evident already from the dramatic difference between the ${ }^{17} \mathrm{O}$ dispersions from BPTI and ubiquitin (see Figure 2).

To quantitatively interpret the parameter $\beta$ we need to examine the local environment of the buried water molecules. Figures 9 to 11 show the location and hydrogen bonding of the four internal water molecules of BPTI in crystal form II (Wlodawer et al ., 1984). (The solution structure of BPTI is nearly identical to the crystal structure (Berndt et al., 1992).) The hydrogen bond geometries for these internal water molecules are summarized in Table 1. One of the four internal water molecules, denoted W122, is completely buried in a very small cavity near the Cys14-Cys38 disulfide bond. The remaining three internal water molecules, denoted W111 to W113, form a hydrogen-bonded chain occupying a pore-like cavity with W111 at its mouth and W113 most deeply buried (approximately $7 \AA$ away from W122). The water molecules W122, W113, and W112 each participate in four strong hydrogen bonds to backbone polar atoms or to each other (and W111). As is evident from Figures 10 and 11, and Table 1, the hydrogen bond environments of these internal water molecules resemble that in hexagonal ice, with 

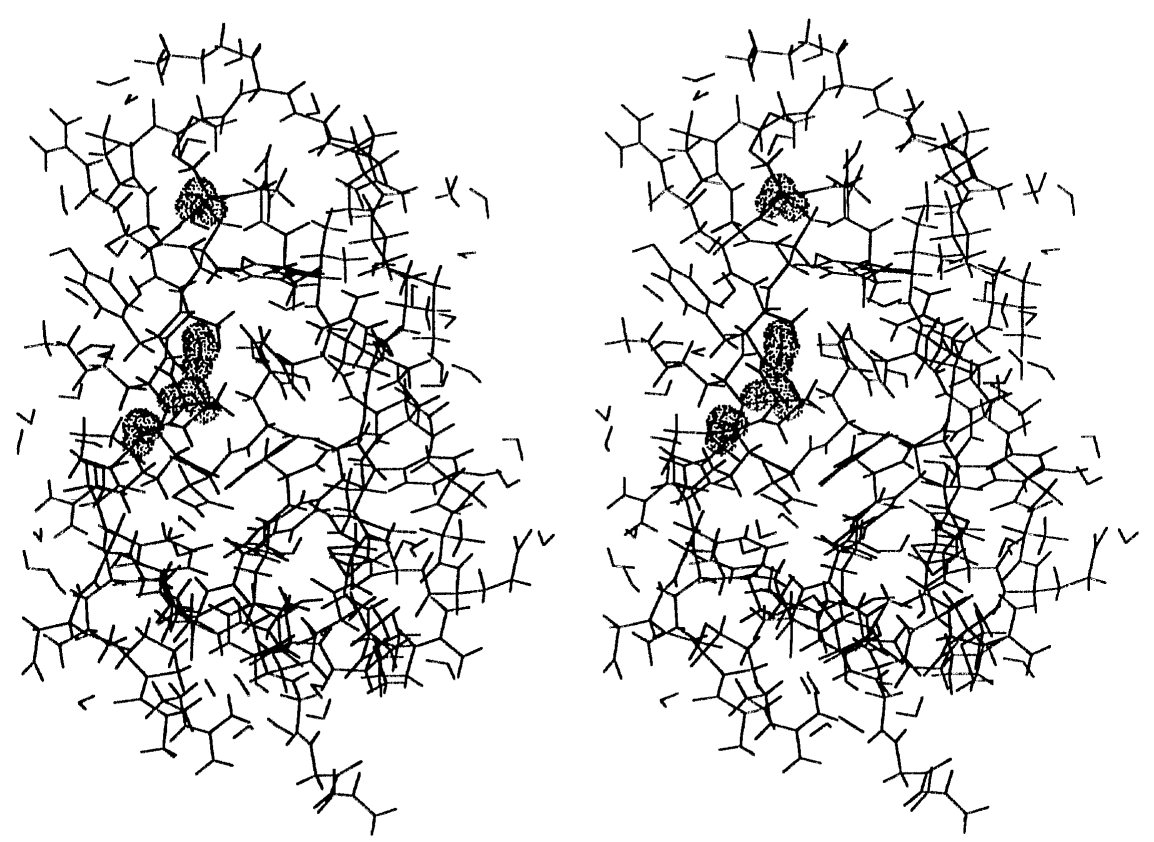

Figure 9. Location of the 4 internal water molecules in BPTI (Wlodawer et al., 1987a; Protein Data Bank, file 5PTI). The dot surfaces of the water molecules correspond to $50 \%$ of the van der Waals radii.

hydrogen bond lengths not very different from the ice Ih value of $2.76 \AA$ (Kuhs \& Lehmann, 1983) and a roughly tetrahedral coordination. W111 participates in three strong hydrogen bonds, one of which involves the side-chain of Glu7. The crystallographic temperature factors $(B)$ of the internal water molecules in BPTI (see Table 1) demonstrate a high degree of positional order, comparable with the main-chain atoms.

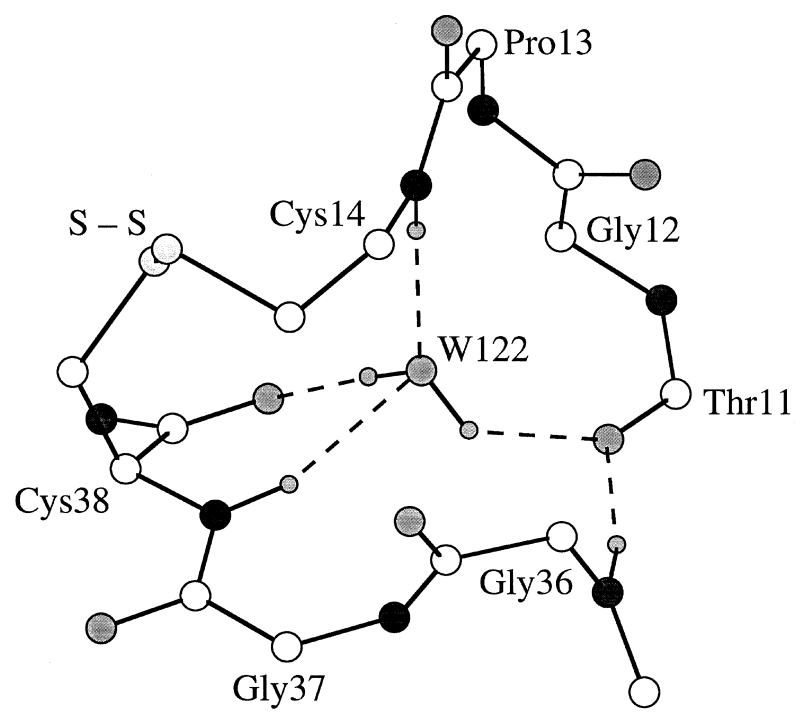

Figure 10. Hydrogen bonding of the internal water molecule W122 in BPTI (Wlodawer et al., 1987a; protein Data Bank, file 5PTI). Only hydrogen atoms that participate in hydrogen bonds are shown.
In ubiquitin an exceptionally high fraction $(87 \%)$ of the main chain is involved in hydrogen-bonded secondary structure and there are no deeply buried water molecules (Vijay-Kumar et al., 1987). However, examination of the crystal structure reveals one water molecule, denoted W28, residing in a surface cleft and forming two strong hydrogen bonds to the main chain and a weaker one involving the side-chain of Lys27 (see Figures 12 and 13, and

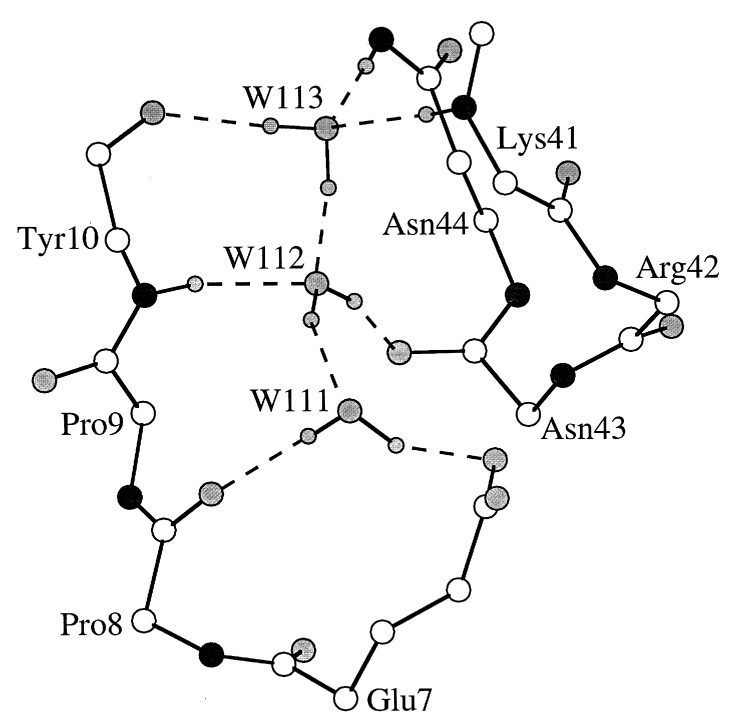

Figure 11. Hydrogen bonding of the internal water molecules W111 to W113 in BPTI (Wlodawer et al., 1987a; Protein Data Bank, file 5PTI). Only hydrogen atoms that participate in hydrogen bonds are shown. 


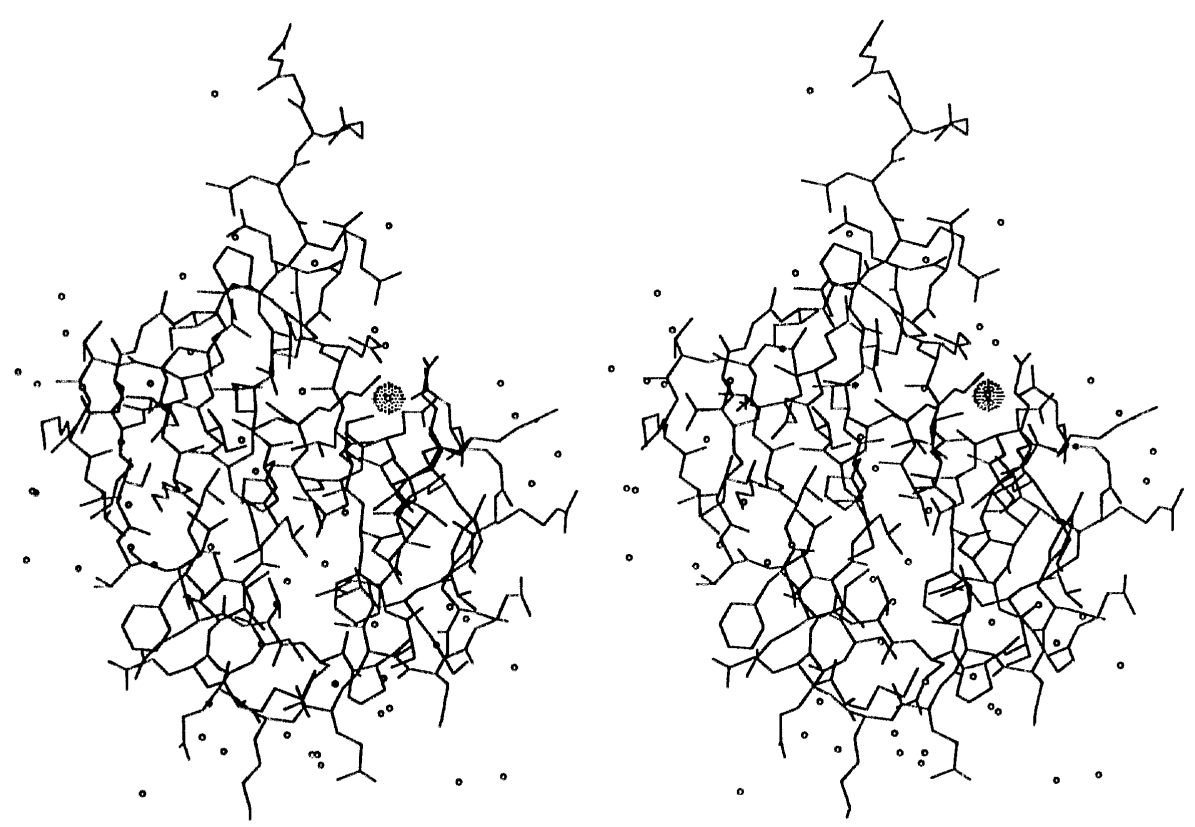

Figure 12. Location of the partly buried water molecule W28 in ubiquitin (Vijay-Kumar et al., 1987; Protein Data Bank, file 1UBQ). The dot surface of the water oxygen atom corresponds to $50 \%$ of the van der Waals radius.

Table 1). The amine nitrogen of Lys27 is also engaged in a hydrogen bond to the carbonyl oxygen of Gln 41 $(3.2 \AA)$ and a salt bridge to one of the carboxylate oxygen atoms of Asp52 (2.9 $\AA)$. In both BPTI and ubiquitin, the water molecules described here extend the intramolecularly hydrogen-bonded secondary structure and thus stabilize the tertiary structure.

The product $N_{\mathrm{I}}\left\langle A_{\mathrm{I}}^{2}\right\rangle$ can be obtained from equation (8b) and the experimental $\beta$ values in Figure 5 as:

$$
N_{\mathrm{I}}\left\langle A_{\mathrm{I}}^{2}\right\rangle=\frac{125}{12 \pi^{2}} \frac{\beta M_{\mathrm{P}}(1-w)}{\left\langle\chi_{\mathrm{I}}^{2}\right\rangle M_{\mathrm{W}} w}
$$

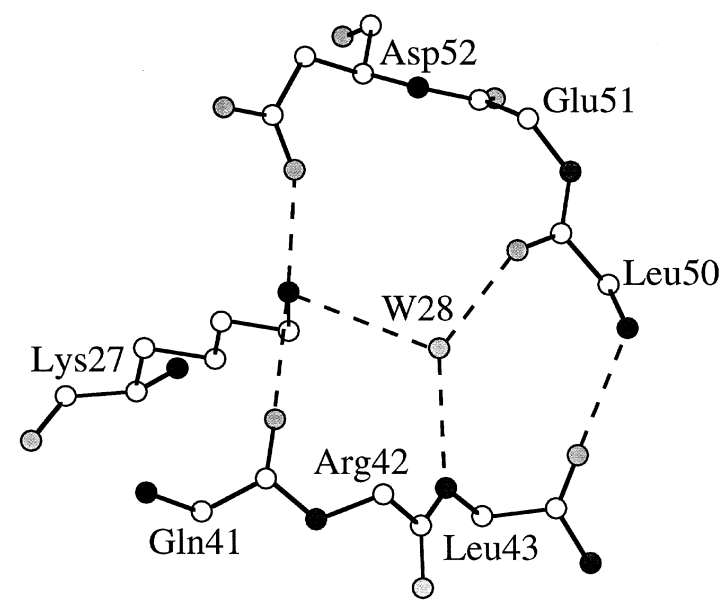

Figure 13. Hydrogen bonding of the partly buried water molecule W28 in ubiquitin (Vijay-Kumar et al., 1987; Protein Data Bank, file 1UBQ). Hydrogen positions have not been determined. provided that we know the ${ }^{17} \mathrm{O}$ quadrupole coupling constant (QCC) $\chi_{\mathrm{I}}$ for the internal waters. (To obtain equation (11) we have neglected correlations between $A_{\mathrm{I}}$ and $\chi_{\mathrm{I}}$ so that $\left\langle A_{\mathrm{I}}^{2} \chi_{\mathrm{I}}^{2}\right\rangle=\left\langle A_{\mathrm{I}}^{2}\right\rangle\left\langle\chi_{\mathrm{I}}^{2}\right\rangle$.) The ${ }^{17} \mathrm{O}$ QCC is determined by the electron distribution around the water oxygen and, hence, is affected by hydrogen-bond-induced electronic polarization (Cummins et al., 1985). The values for $\chi_{\mathrm{I}}$ in ice Ih, liquid, and vapour are, respectively, $6.5 \mathrm{MHz}$ (Spiess et al., 1969; Edmonds \& Zussman, 1972), 8.1 MHz (van der Maarel et al., 1985; Struis et al., 1987; Eggenberger et al., 1993), and 10.2 MHz (Verhoeven et al., 1969). An estimate of the ${ }^{17} \mathrm{O}$ QCC for the internal water molecules of BPTI may be obtained as follows. Using empirical relationships (Berglund et al., 1978), based on crystal hydrate data, between the water deuteron QCC $\chi\left({ }^{2} \mathrm{H}\right)$ and the hydrogen bond geometry, we obtain with the data in Table 1 an average $\chi\left({ }^{2} \mathrm{H}\right)$ of $213 \mathrm{kHz}$ and a root-mean-square variation of $18 \mathrm{kHz}$ for the eight internal water deuterons of BPTI. This should be compared with the value $\chi\left({ }^{2} \mathrm{H}\right)=213.4 \mathrm{kHz}$ for ${ }^{2} \mathrm{H}_{2} \mathrm{O}$ ice Ih (Edmonds \& Mackay, 1975). Since it is known empirically (Poplett, 1982) that $\chi\left({ }^{17} \mathrm{O}\right)$ exhibits the same linear dependence on $\chi\left({ }^{2} \mathrm{H}\right)$ in numerous crystal hydrates as in the ice polymorphs, we conclude that the average $\chi\left({ }^{17} \mathrm{O}\right)$ for the four internal water molecules of BPTI should be close to $\chi\left({ }^{17} \mathrm{O}\right)$ for ice Ih. With $\chi_{\mathrm{I}}=6.5 \mathrm{MHz}$ inserted into equation (11), we find from the BPTI data in Figure 5 that $N_{\mathrm{I}}\left\langle A_{\mathrm{I}}^{2}\right\rangle$ varies from 2.3 $( \pm 0.1)$ at $\mathrm{pD} 1.9$ to $1.9( \pm 0.1)$ at $\mathrm{pD}$ 10.7. From the ubiquitin data in Figure 5 we find, in the same way, that $N_{\mathrm{I}}\left\langle A_{\mathrm{I}}^{2}\right\rangle$ varies from $0.21( \pm 0.04)$ at $\mathrm{pD} 1.9$ to $0.40( \pm 0.04)$ at pD 10.5.

Since the internal water molecules of BPTI are extensively linked to the protein backbone by strong 
hydrogen bonds (see Figures 10 and 11, and Table 1), they should exhibit a high degree of orientational order. In the presence of small-amplitude librational oscillations, we find for the square of the generalized ${ }^{17} \mathrm{O}$ order parameter:

$$
A_{\mathrm{I}}^{2}=1+\frac{1}{3} \eta^{2}-2\left[1-\frac{1}{3} \eta(1-\eta)\right]\left\langle\theta^{2}\right\rangle,
$$

with $\eta$ the asymmetry parameter of the ${ }^{17} \mathrm{O}$ electric field gradient tensor and $\left\langle\theta^{2}\right\rangle$ the mean-square libration angle. (Equation (12) gives the average $A_{I}^{2}$ for librations around the three orthogonal principal axes of the ${ }^{17} \mathrm{O}$ electric field gradient tensor.) Adopting the ice Ih value, $\eta=0.93$ (Speiss et al., 1969; Edmonds \& Zussman, 1972), we thus find that $A_{1}^{2}$ varies from 1.29 in the absence of libration to 1.05 for $\left\langle\theta^{2}\right\rangle^{1 / 2}=20^{\circ}$, corresponding to the typical libration amplitude for peptide $\mathrm{N}-\mathrm{H}$ bonds in globular proteins, as obtained from ${ }^{15} \mathrm{~N}$ relaxation and the relation $A_{\mathrm{NH}}^{2} \approx 1-(3 / 2)\left\langle\theta^{2}\right\rangle \approx 0.85$ (Wagner, 1993; and references cited therein). Another possible type of internal motion is a $180^{\circ}$ flip around the $C_{2}$ axis of the water molecule. Due to symmetry, however, this motion does not affect $A_{\mathrm{I}}$ for ${ }^{17} \mathrm{O}$ and, besides, is probably orders of magnitude too slow (Fujara et al., 1988; Wittebort et al., 1988; Larsson et al., 1991) to contribute to motional averaging on the time-scale $\left(\tau_{\mathrm{R}}\right)$ on which the time correlation function decays.

Data on the orientational order of internal water molecules have been reported from only one (Levitt, 1983) of the numerous simulation studies performed on BPTI. This early study included the water molecules W122, W113, W112, and W143. (Although W143 resides in a cleft, it participates in only one hydrogen bond shorter than $3 \AA$ and is not classified as internal.) According to the simulation, W122 and W113 are highly ordered, with $\mathrm{O}-\mathrm{H}$ bond order parameters $S_{\mathrm{OH}}$ of 0.9 and 0.8 , respectively. With $S_{\mathrm{OH}} \approx 1-(3 / 2)\left\langle\theta^{2}\right\rangle$, this corresponds to $\left\langle\theta^{2}\right\rangle^{1 / 2}=15$ to $20^{\circ}$. In contrast, W112 and W143 were both found to be relatively weakly ordered, with $S_{\mathrm{OH}} \approx 0.1$. However, due to the absence of any external water in this vacuum simulation, the accuracy of these results is uncertain. In particular, the omission of W111 could have a large effect on $S_{\mathrm{OH}}$ of W112.

In the neutral pD range we find that $N_{\mathrm{I}}\left\langle A_{\mathrm{I}}^{2}\right\rangle$ equals 2.1 $( \pm 0.1)$ for BPTI and $0.26( \pm 0.05)$ for ubiquitin. Although the present data do not allow us to directly infer the identity of the water molecules responsible for these values, it is tempting to associate these values with the five buried water molecules shown in Figures 10, 11, and 13. Judging from the hydrogen bond environments, W122, W113, and W112 (in BPTI) should be highly ordered, with $A$ approaching 1, while W111 (in BPTI) and W28 (in ubiquitin) should be somewhat less ordered. If this is correct, the value $N_{\mathrm{I}}\left\langle A_{\mathrm{I}}^{2}\right\rangle=2.1$ can account for only two of the three highly ordered water molecules in BPTI.

A large (generalized) order parameter $A$ is a necessary, but not a sufficient, condition for a water molecule to contribute substantially to the relaxation dispersion and, hence, to $\beta$ and $N_{\mathrm{I}}\left\langle A_{\mathrm{I}}^{2}\right\rangle$. In addition, the mean residence time $\tau_{\text {res }}$ of the water molecule must obey the inequalities:

$$
\tau_{\mathrm{R}}<\tau_{\text {res }}<1 / R_{\mathrm{I}} .
$$

The water molecule must be associated with the protein for a long time compared to $\tau_{\mathrm{R}}$ in order to sense the Brownian rotation of the protein and, thereby, contribute to the observed dispersion. On the other hand, $\tau_{\text {res }}$ must be short compared to the intrinsic ${ }^{17} \mathrm{O}$ spin relaxation time (at zero frequency) in order for the water binding site to act as a relaxation sink for the bulk water magnetization and, hence, contribute to the observed relaxation enhancement at low frequencies. According to equation $(8 \mathrm{~b}), R_{\mathrm{I}}=\left(12 \pi^{2} / 125\right)\left\langle A_{\mathrm{I}}^{2} \chi_{\mathrm{I}}^{2}\right\rangle \tau_{\mathrm{R}}$. With $A_{\mathrm{I}}=1$, $\chi_{\mathrm{I}}=6.5 \mathrm{MHz}$, and $\tau_{\mathrm{R}}=7 \mathrm{~ns}$, we thus find that a highly ordered water molecule contributes to the relaxation enhancement if:

$$
7 \mathrm{~ns}<\tau_{\text {res }}<4 \mu \mathrm{s} \text {. }
$$

The recent high-resolution ${ }^{1} \mathrm{H}$ NMR study of BPTI in solution demonstrates that $\tau_{\text {res }}>0.3 \mathrm{~ns}$ for all four internal water molecules (Otting \& Wüthrich, 1989). This lower bound on $\tau_{\text {res }}$ follows from the sign of the observed NOE cross-peak if internal motion is neglected. Using a paramagnetic shift reagent, it has also been established that $\tau_{\text {res }}<20 \mathrm{~ms}$ at $4^{\circ} \mathrm{C}$ for (the protons of) the internal water molecules of BPTI (Otting et al., 1991b). This still leaves a range of four orders of magnitude $\left(10^{-6}\right.$ to $\left.10^{-2} \mathrm{~s}\right)$ for $\tau_{\text {res }}$, where an internal water molecule would exchange too slowly to contribute to the ${ }^{17} \mathrm{O}$ relaxation. Simple energetic considerations suggest that the internal water molecules (with the possible exception of W111) of BPTI exchange with the external water via conformational fluctuations that temporarily expose the buried water molecules, rather than via diffusive escape of the individual water molecules from their cavities. We thus expect that W113 and W112 (and perhaps W111) exchange at the same rate, which may differ substantially from the exchange rate of W122. Since W122 is completely enclosed in a very small cavity in a rigid part of the protein (near a disulfide bond), it is probably the most slowly exchanging of the four internal water molecules in BPTI.

We can now formulate a tentative interpretation of the $\beta$ values obtained from our ${ }^{17} \mathrm{O}$ relaxation data for BPTI and ubiquitin. For BPTI, the main contribution to the ${ }^{17} \mathrm{O}$ relaxation dispersion comes from $\mathrm{W} 113$ and W112, with $A$ close to 1 and $\tau_{\text {res }}$ in the range of equation (13b). W122 probably exchanges too slowly to contribute $\left(\tau_{\text {res }}>4 \mu \mathrm{s}\right)$, while the less strongly hydrogen-bonded W111 has a lower orientational order (say, $A \approx 0.5$ ) and makes a correspondingly smaller contribution. The assertion that one of the four internal water molecules of BPTI exchanges too slowly to contribute to the ${ }^{17} \mathrm{O}$ dispersion is supported by the ${ }^{2} \mathrm{H}$ relaxation data presented in the accompanying paper (Denisov \& Halle, 1995). A decisive test of these tentative assignments would be to measure the ${ }^{17} \mathrm{O}$ relaxation dispersion from BPTI mutants with one or more of the four internal water molecules displaced (Housset et al., 1991; Berndt et al., 1993). 
For ubiquitin, the small ${ }^{17} \mathrm{O}$ relaxation dispersion is due entirely to W28, which then must have $A \approx 0.5$. W28 in ubiquitin is, indeed, expected to be similar to W111 in BPTI, since both participate in three hydrogen bonds, one of which involves a side-chain. It should be noted, however, that, according to the usual criterion for internal water (no hydrogen bond to external water), W111 in BPTI is internal while W28 is classified as surface water. The identification of W28 as the sole contributor to the ubiquitin dispersion is further supported by the $\mathrm{pD}$ dependence of $\beta$ (see Figure 5), which could indicate an effect on the internal motion (and, hence, on $A$ ) of W28 due to disruption of the salt bridge when Lys27 and Asp52 are titrated (see Figure 13). The case of W28 in ubiquitin demonstrates that not only internal but also surface water molecules can have long (> nanosecond) residence times. As discussed in Concluding Discussion, below, this is not likely to be a direct consequence of extensive hydrogen-bonding, as suggested in the case of two long-lived surface water molecules in streptococcal protein G (Clore \& Gronenborn, 1992), but requires that the water is located in a pocket on the protein surface. In the case of BPTI, the crystal structure does not reveal any strongly hydrogen-bonded surface water molecules in pockets.

\section{Concluding Discussion}

Over the past three decades an extensive literature on nuclear spin relaxation in aqueous protein systems has accumulated. The failure of this massive body of experimental data to provide a coherent picture of protein hydration demonstrates that the interpretation of such data is non-trivial. The divergent pictures of protein hydration (especially its dynamic aspects) derived from spin relaxation studies can be largely blamed on three complicating factors. First, as is now generally recognized, the ${ }^{1} \mathrm{H}$ relaxation is dominated by cross-relaxation effects and therefore cannot be interpreted solely in terms of water dynamics (Edzes \& Samulski, 1978; Koenig et al., 1978; Hills, 1992). Second, ${ }^{1} \mathrm{H}$ and ${ }^{2} \mathrm{H}$ relaxation both contain significant contributions from labile protein hydrogens that exchange with water (Piculell \& Halle, 1986; Hills et al., 1989; Hills, 1992). This effect, which in the accompanying paper is quantitatively established by comparing the $\mathrm{pD}$ dependence of the ${ }^{2} \mathrm{H}$ and ${ }^{17} \mathrm{O}$ relaxation dispersions (Denisov \& Halle, 1995), has usually been neglected (Kimmich et al., 1990; Koenig \& Brown, 1991; Koenig et al., 1993). Third, since the observed relaxation dispersion represents an average over a large number of water molecules in different local environments, it is particularly important to design experiments that can decisively test the proposed models. This has rarely been done.

In the present work, by studying the relaxation of water ${ }^{17} \mathrm{O}$ nuclei, we completely avoided the complications of cross-relaxation and hydrogen exchange. Moreover, by contrasting the relaxation behaviour of the proteins BPTI and ubiquitin, we could decisively test the hypothesis that internal water plays a significant role. The picture emerging from the present study is one of a highly mobile hydration layer at the protein surface, with an average reorientational correlation time of approximately 20 picoseconds $\left({ }^{2} \mathrm{H}_{2} \mathrm{O}, 27^{\circ} \mathrm{C}\right)$ and, presumably, a similar average residence time, and a small number (three in BPTI) of highly ordered water molecules (partially) buried but exchanging with bulk water (presumably via partial unfolding of the dominant protein conformation) on a time-scale of $10^{-8}$ to $10^{-6}$ second. This picture is consistent, not only with the crystal structures (Deisenhofer \& Steigemann, 1975; Wlodawer et al., 1984, 1987a,b), but also with the recent high-resolution ${ }^{1} \mathrm{H}$ NMR studies (Otting \& Wüthrich, 1989; Otting et al., 1991a) and computer simulations (Brunne et al., 1993) of BPTI. Our upper bound of four microseconds for the residence time of the exchanging internal water molecules is a factor 5000 lower than (but consistent with) the result from paramagnetic shift experiments (Otting et al., 1991b) and a factor $4 \times 10^{6}$ lower than the result from ${ }^{18} \mathrm{O}$ gel filtration experiments (Tüchsen et al., 1987). Furthermore, we believe that our picture of protein hydration is consistent with previous relaxation dispersion data, although not with all conclusions drawn therefrom. For example, from a recent ${ }^{2} \mathrm{H}$ relaxation dispersion study of serum albumin solutions it was concluded that the residence times of the several hundred surface water molecules exceed $10^{-6}$ second (Kimmich et al., 1990). Finally, the identification of internal water molecules as the source of the ${ }^{17} \mathrm{O}$ relaxation dispersion in protein solutions is consistent with the failure to observe similar manifestations of long water residence times in systems with amphiphilic aggregates (Carlström \& Halle, 1989), where water does not penetrate into the hydrocarbon region.

An important result of the present study is the realization that the high-frequency ( $\alpha$ term) and low-frequency ( $\beta$ term) relaxation contributions are due to two different classes of water molecules. This removes the internal inconsistencies that led some authors (Koenig et al., 1975; Bryant, 1988; Koenig \& Brown, 1991) to reject a simple fast-exchange model. Furthermore, the hitherto controversial mechanism whereby the protein rotational motion is conveyed to the water molecules (Bryant, 1988) is now identified as the exchange, on the time-scale $10^{-8}$ to $10^{-6}$ second (for ${ }^{17} \mathrm{O}$ relaxation and small proteins), of highly ordered internal water molecules. From a recent ${ }^{2} \mathrm{H}$ relaxation dispersion study of chemically cross-linked serum albumin it was concluded that the ${ }^{2} \mathrm{H}$ dispersion is due to approximately eight "strongly bound" water molecules at the protein surface with a (temperature independent!) residence time of one microsecond (Koenig et al., 1993). Although this interpretation may appear to be in line with the present results, it can be shown that the dispersion frequency in this experiment is not related to water dynamics but, rather, is an effect of the break-down of the second-order perturbation 
theory of spin relaxation (B. Halle, unpublished results).

Since ${ }^{1} \mathrm{H}$ and ${ }^{2} \mathrm{H}$ relaxation are complicated by cross-relaxation and hydrogen exchange, a detailed discussion of previous results obtained with these nuclei will not be attempted here. Rather, we focus on the more readily interpreted ${ }^{17} \mathrm{O}$ relaxation data reported earlier (Halle et al., 1981; Piculell \& Halle, 1986; Halle \& Piculell, 1986). While essentially the same conclusions as here were reached about the fast rotation of surface water molecules, it was also shown that the low-frequency relaxation contribution ( $\beta$ term) could be consistently accounted for in terms of the same (weakly ordered) surface water molecules whose fast (but orientationally restricted) rotation is responsible for the high-frequency contribution ( $\alpha$ term). This required, however, a large number of surface water molecules to have residence times exceeding $10^{-8}$ second, which is now known to be inconsistent with high-resolution ${ }^{1} \mathrm{H}$ NMR data (Otting \& Wüthrich, 1989; Otting et al., 1991a) as well as with simulation data (Ahlström et al., 1988; Brunne et al., 1993). A strong argument in favor of the previous interpretation, with no contribution from internal water molecules, was the finding that the ratio $\alpha / \beta$ (see equation (10)) was nearly constant for the proteins examined (parvalbumin, cytochrome $c$, lysozyme, haemoglobin, and serum albumin). In the light of the present study, however, we can conclude that the near invariance of $\alpha / \beta$ was due to a coincidental approximate proportionality between $N_{\mathrm{I}}\left\langle A_{\mathrm{I}}^{2}\right\rangle$ and $N_{\mathrm{S}}$ for these proteins. Proteins, such as the serine proteases, which are known to contain as many as 20 internal water molecules (Sreenivasan \& Axelsen, 1992), should also deviate from this picture and preliminary ${ }^{17} \mathrm{O}$ experiments confirm this (our unpublished results).

The BPTI solutions studied here contain approximately 2400 bulk water molecules per protein molecule, approximately 250 surface, and three (rapidly exchanging) internal water molecules. These three classes of water molecules contribute, respectively, 36,16 , and $48 \%$ of the ${ }^{17} \mathrm{O}$ relaxation rate $R_{1}$ at the lowest frequency and 65,28 , and $7 \%$ at the highest frequency. The reason that three internal water molecules can contribute more than 2400 bulk ones is that they reorient (along with the protein) approximately 2000 times slower than in the bulk. For this dynamic relaxation enhancement to be effective, the water molecules must (1) be highly ordered ( $A$ close to 1$)$ and (2) have a long (but not too long) residence time $\left(\tau_{\mathrm{R}}<\tau_{\text {res }}<1 / R_{\mathrm{I}}\right)$. Roughly speaking, the size of the dispersion step (i.e. $\beta$ ) is proportional to the quantity $\Sigma_{i} A_{i}^{2} \tau_{\mathrm{res}, i} /\left(\tau_{\mathrm{res}, i}+\tau_{\mathrm{R}}\right)$, summed over all water molecules in the system for which $\tau_{\text {res }, i}<1 / R_{\mathrm{I}, i}$.

Although the residence times in the range seven nanoseconds to four microseconds obtained here for the internal water molecules of BPTI are orders of magnitude shorter than previous estimates, they are still very long when compared to the translational mobility of bulk water, where displacements over a molecular diameter occur in less then ten picosec- onds. We believe that the essential property of internal water molecules that produces this dramatic reduction of their translational mobility is not the interaction with the protein per se (most external water molecules are also extensively hydrogenbonded), but rather their physical entrapment within the protein matrix. Accordingly, these long-lived water molecules are more appropriately referred to as internal, trapped or buried, rather than as strongly interacting or bound.

It appears that a long ( $>$ nanosecond) residence time can result only if a water molecule resides in an internal cavity or in a surface pocket of appropriate structure. For a water molecule in a cavity, the residence time should be determined primarily by the energetics of local unfolding rather than by the energetics of water-protein interactions within the cavity, the latter determining the equilibrium occupancy of the cavity. For a water molecule in a surface pocket, the residence time should be determined not by the number of water-protein hydrogen bonds per se, but rather by the activation energy needed for the water molecule to pass through the least hydrogen-bonded state on its way out of the pocket. In conclusion, the commonly quoted requirement of strong hydrogen bonding is neither necessary nor sufficient for a long residence time.

In contrast to the exchange of buried peptide amide hydrogen atoms (Wagner, 1983), the exchange of internal water molecules should be rate-limited by local unfolding of the dominant protein conformation. Apart from providing the rotational correlation time of the protein, the ${ }^{17} \mathrm{O}$ relaxation dispersion may thus prove useful for studies of internal protein dynamics on the time-scale $10^{-8}$ to $10^{-6}$ second. Primarily, however, ${ }^{17} \mathrm{O}$ relaxation is a valuable source, complementary to $\mathrm{X}$-ray and neutron diffraction and high-resolution multidimensional ${ }^{1} \mathrm{H}$ NMR, of information about structurally and functionally significant water molecules in globular proteins and other biomolecules.

\section{Materials and Methods}

\section{Protein solutions}

Recombinant bovine pancreatic trypsin inhibitor $(M$ $6500 \mathrm{~g} \mathrm{~mol}^{-1}$ ), a gift from Novo Nordisk A/S, was obtained as a lyophilized powder (Aprotinin, batch no. A46R02, $99.5 \%$ pure). Ubiquitin ( $M 8560 \mathrm{~g} \mathrm{~mol}^{-1}$ ) from bovine red blood cells was obtained from Sigma as a lyophilized powder (catalogue no. U6253). The purity of the ubiquitin preparation was assessed by gel electrophoresis, indicating less than $1 \%$ contaminating protein. Both proteins were used as supplied, without further purification.

Protein solutions were made from heavy water $(M$ $21.5 \mathrm{~g} \mathrm{~mol}^{-1}$ ), enriched in ${ }^{17} \mathrm{O}$ (Ventron, 21.9 atom $\%{ }^{17} \mathrm{O}, 61.9$ atom $\%{ }^{18} \mathrm{O}, 99.95$ atom $\left.\%{ }^{2} \mathrm{H}\right) . \mathrm{pH}$ was measured with a Radiometer PHM63 digital pH-meter equipped with a $5 \mathrm{~mm}$ combination electrode. The direct reading $\mathrm{pH}^{*}$ from a ${ }^{2} \mathrm{H}_{2} \mathrm{O}$ solution (with the $\mathrm{pH}$ meter calibrated with 
standard $\mathrm{H}_{2} \mathrm{O}$ buffers) was converted to thermodynamically meaningful $\mathrm{pD}$ values according to $\mathrm{pD}=\mathrm{pH}^{*}+0.41$ (Covington et al., 1968). Desired pD values were obtained by adding small amounts of $5 \mathrm{M} \mathrm{HCl}$ or $5 \mathrm{M} \mathrm{KOH}$ to the protein solutions.

Protein concentrations were determined by complete amino acid analysis, which also confirmed the high purity of the protein preparations (see above) and demonstrated a negligible loss of terminal $\mathrm{Gly}_{2}$ dipeptide in ubiquitin. The protein concentrations obtained in this way were $10.4( \pm 0.2) \% \quad(\mathrm{w} / \mathrm{w}) \quad$ BPTI and $10.2( \pm 0.2) \% \quad(\mathrm{w} / \mathrm{w})$ ubiquitin. The small $(<5 \%)$ variation of protein concentration due to $\mathrm{pD}$ adjustments was compensated for in the data analysis.

\section{Relaxation dispersion measurements}

Oxygen-17 relaxation rates were measured at eight magnetic field strengths: (1) at $8.5 \mathrm{~T}$ on a Nicolet 360 spectrometer; (2) at $7.0 \mathrm{~T}$ on a Varian Unity 300 spectrometer; (3) at $2.35 \mathrm{~T}$ on a Bruker MSL 100 spectrometer; and (4) at 1.83, 1.505, 1.05, 0.7 and $0.45 \mathrm{~T}$ using an iron magnet (Drusch EAR-35N) equipped with field-variable lock and flux stabilizer and operated from the MSL 100 spectrometer. The sample temperature was adjusted to $27.00( \pm 0.05)^{\circ} \mathrm{C}$ using a copper-constantan thermocouple, and was maintained to within $\pm 0.05 \mathrm{deg}$. C $( \pm 0.1 \mathrm{deg}$. $C$ on the Varian spectrometer $)$ by a thermostated air flow. NMR tubes with an outer diameter of $10 \mathrm{~mm}$ were used, with sample volumes ranging from 0.7 to $1.7 \mathrm{ml}$.

Longitudinal relaxation rates were measured by the inversion recovery pulse sequence $\left(180^{\circ}-\tau-90^{\circ}\right)$, and transverse relaxation rates by the spin-echo pulse sequence $\left(90^{\circ}-\tau-180^{\circ}-\tau\right)$. The $180^{\circ}$ pulse angle was calibrated to within $1^{\circ}$ before each measurement, and the $90^{\circ}$ pulse length was set to half that of the $180^{\circ}$ pulse. Phase cycling was used to eliminate residual pulse length and phase errors. At least 16 transients (one full phase cycle) were accumulated for each $\tau$ value. At the lowest fields, up to 4096 transients were accumulated to maintain a signal-to-noise ratio of at least 100 . Each relaxation experiment comprised $20 \tau$ values (in random order) in the interval $(0.05-5.3) T$, with $T=T_{1}$ or $T_{2}$. The relaxation rates $R_{1}=1 / T_{1}$ and $R_{2}=1 / T_{2}$ were determined from exponential fits to the 20 data points using standard software. Although the relaxation of a spin $I=5 / 2$ nucleus like ${ }^{17} \mathrm{O}$ is in principle tri-exponential in isotropic solution (Abragam, 1961), theoretical considerations (Halle \& Wennerström, 1981b) show that the simple exponential approximation (see Results and Discussion, Oxygen-17 spin relaxation of water in protein solutions) is accurate to better than $0.1 \%$ under the conditions of the present study. As expected, no signs of multi-exponential relaxation could be detected. The accuracy of the determined relaxation rates was estimated to be better than $1 \%$ for $R_{1}$ and $1.5 \% R_{2}$.

Relaxation rates for bulk water of the same isotopic composition as in the protein solutions (but adjusted to $\mathrm{pD}$ 3.5 to avoid contributions from scalar relaxation to $R_{2}$ (Halle \& Karlström, 1983)) were measured ten times within several months and at different fields, with the result: $R_{1}=175( \pm 1) \mathrm{s}^{-1}$ and $R_{2}=176( \pm 2) \mathrm{s}^{-1} \cdot R_{2}$ values measured on the Nicolet spectrometer showed a systematic error ( 3 to $5 \%$ ) of unknown origin, and were therefore not used in the data analysis.

Non-linear fits of theoretical expressions (see Results and Discussion, Oxygen-17 spin relaxation of water in protein solutions) to the combined $R_{1}$ and $R_{2}$ dispersion data (15 data points) were made with the LevenbergMarquardt algorithm.

\section{Acknowledgements}

We thank Novo Nordisk A/S, Gentofte, Denmark for a gift of BPTI and Eva Thulin for performing the electrophoretic assay. Financial support from the WennerGren Center Foundation for Scientific Research (to V.D.), the Swedish Natural Science Research Council (to B.H.), and the Swedish Council for Planning and Coordination of Research (field-variable magnet) is gratefully acknowledged.

\section{References}

Abragam, A. (1961). The Principles of Nuclear Magnetism. Clarendon Press, Oxford.

Ahlström, P., Teleman, O. \& Jönsson, B. (1988). Molecular dynamics simulation of interfacial water structure and dynamics in a parvalbumin solution. J. Amer. Chem. Soc. 110, 4198-4203.

Baker, E. N. \& Hubbard, R. E. (1984). Hydrogen bonding in globular proteins. Progr. Biophys. Mol. Biol. 44, 97-179.

Belton, P.S. (1994). NMR studies of protein hydration. Progr. Biophys. Mol. Biol. 61, 61-79.

Berglund, B., Lindgren, J. \& Tegenfeldt, J. (1978). On the correlation between deuteron quadrupole coupling constants, $\mathrm{O}-\mathrm{H}$ and $\mathrm{O}-\mathrm{D}$ stretching frequencies and hydrogen-bond distances in solid hydrates. J. Mol. Struct. 43, 179-191.

Berndt, K. D., Güntert, P., Orbons, L. P. M. \& Wüthrich, K. (1992). Determination of a high-quality nuclear magnetic resonance solution structure of the bovine pancreatic trypsin inhibitor and comparison with three crystal structures. J. Mol. Biol. 227, 757-775.

Berndt, K. D., Beunink, J., Schröder, W. \& Wüthrich, K. (1993). Designed replacement of an internal hydration water molecule in BPTI: structural and functional implications of a glycine-to-serine mutation. Biochemistry, 32, 4564-4570.

Brown, L. R., de Marco, A., Richarz, R., Wagner, G. \& Wüthrich, K. (1978). The influence of a single salt bridge on static and dynamic features of the globular solution conformation of the basic pancreatic trypsin inhibitor. Eur. J. Biochem. 88, 87-95.

Brunne, R. M., Liepinsh, E., Otting, G., Wüthrich, K. \& van Gunsteren, W. F. (1993). Hydration of proteins. A comparison of experimental residence times of water molecules solvating bovine pancreatic trypsin inhibitor with theoretical model calculations. J. Mol. Biol. 231, 1040-1048.

Bryant, R. G. (1988). Magnetic resonance and macromolecule solvation dynamics. In The Chemical Physics of Solvation (Dogonadze, R. R., Kálmán, E., Kornyshev, A. A. \& Ulstrup, J., eds), part C, pp. 683-705, Elsevier, Amsterdam.

Carlström, G. \& Halle, B. (1989). Shape fluctuations and water diffusion in microemulsion droplets. A nuclear spin relaxation study. J. Phys. Chem. 93, 3287-3299.

Clore, G. M. \& Gronenborn, A. M. (1992). Localization of bound water in the solution structure of the immunoglobulin binding domain of streptococcal protein G. Evidence for solvent-induced helical distortion in solution. J. Mol. Biol. 223, 853-856.

Clore, G. M, Bax, A., Wingfield, P. T. \& Gronenborn, A. M. (1990). Identification and localization of bound internal water in the solution structure of interleukin 
$1 \beta$ by heteronuclear three-dimensional ${ }^{1} \mathrm{H}$ rotatingframe Overhauser ${ }^{15} \mathrm{~N}-{ }^{1} \mathrm{H}$ multiple quantum coherence NMR spectroscopy. Biochemistry, 29, 5671-5676.

Covington, A. K., Paabo, M., Robinson, R. A. \& Bates, R. G. (1968). Use of the glass electrode in deuterium oxide and the relation between the standardized $\mathrm{pD}\left(\mathrm{pa}_{\mathrm{D}}\right)$ scale and the operational $\mathrm{pH}$ in heavy water. Anal. Chem. 40, 700-706.

Cummins, P. L., Bacskay, G. B., Hush, N. S., Halle, B. \& Engström, S. (1985). The effect of intermolecular interactions on the ${ }^{2} \mathrm{H}$ and ${ }^{17} \mathrm{O}$ quadrupole coupling constants in ice and liquid water. J. Chem. Phys. 82, 2002-2013.

Daggett, V. \& Levitt, M. (1993). Realistic simulations of native-protein dynamics in solution and beyond. Annu. Rev. Biophys. Biomol. Struct. 22, 353-380.

Deisenhofer, J. \& Steigemann, W. (1975). Crystallographic refinement of the structure of bovine pancreatic trypsin inhibitor at $1.5 \AA$ resolution. Acta Crystallogr. sect. $B, 31,238-250$.

Denisov, V. P. \& Halle, B. (1995). Hydrogen exchange and protein hydration. The deuteron spin relaxation dispersions of BPTI and ubiquitin. J. Mol. Biol. 245, 698-709.

Edmonds, D. T. \& Mackay, A. L. (1975). The pure quadrupole resonance of the deuteron in ice. J. Magn. Reson. 20, 515-519.

Edmonds, D. T. \& Zussman, A. (1972). Pure quadrupole resonance of ${ }^{17} \mathrm{O}$ in ice. Phys. Letters, 41A, 167-169.

Edsall, J. T. \& McKenzie, H. A. (1983). Water and proteins. II: The location and dynamics of water in protein systems and its relation to their stability properties. Advan. Biophys. 16, 53-183.

Edzes, H. T. \& Samulski, E. T. (1978). The measurement of cross-relaxation effects in the proton NMR spin-lattice relaxation of water in biological systems: hydrated collagen and muscle. J. Magn. Reson. 31, 207-229.

Eggenberger, R., Gerber, S., Huber, H., Searles, D. \& Welker, M. (1993). The use of molecular dynamics simulations with $a b$ initio SCF calculations for the determination of the oxygen-17 quadrupole coupling constant in liquid water. Mol. Phys. 80, 1177-1182.

Finney, J. L. (1979). The organization and function of water in protein crystals. In Water, A Comprehensive Treatise (Franks, F., ed.), vol. 6, chapt. 2, pp. 47-122, Plenum Press, New York.

Forman-Kay, J. D., Gronenborn, A. M., Wingfield P. T. \& Clore, G. M. (1991). Determination of the positions of bound water molecules in the solution structure of reduced human thioredoxin by heteronuclear threedimensional nuclear magnetic resonance spectroscopy. J. Mol. Biol. 220, 209-216.

Fujara, F., Wefing, S. \& Kuhs, W. F. (1988). Direct observation of tetrahedral hydrogen jumps in ice Ih. J. Chem. Phys. 88, 6801-6809.

Grzesiek, S., Bax, A., Nicholson, L. K., Yamazaki, T., Wingfield, P., Stahl, S. J., Eyermann, C. J., Torchia, D. A., Hodge, C. N., Lam, P. Y. S., Jadhav, P. K. \& Chang, C.-H. (1994). NMR evidence for the displacement of a conserved interior water molecule in HIV protease by a non-peptide cyclic urea-based inhibitor. J. Amer. Chem. Soc. 116, 1581-1582.

Halle, B. \& Karlström, G. (1983). Protropic charge migration in water. Part 1 . Rate constants in light and heavy water and in salt solution from oxygen-17 spin relaxation. J. Chem. Soc. Faraday Trans. 2, 79, 1031-1046.

Halle, B. \& Piculell, L. (1986). Water spin relaxation in colloidal systems. Part 3. Interpretation of the low-frequency dispersion. J. Chem. Soc. Faraday Trans. $1,82,415-429$.

Halle, B. \& Wennerström, H. (1981a). Interpretation of magnetic resonance data from water nuclei in heterogeneous systems. J. Chem. Phys. 75, 1928-1943.

Halle, B. \& Wennerström, H. (1981b). Nearly exponential quadrupolar relaxation. A perturbation treatment. J. Magn. Reson. 44, 89-100.

Halle, B., Andersson, T., Forsén, S. \& Lindman, B. (1981). Protein hydration from water oxygen-17 magnetic relaxation. J. Amer. Chem. Soc. 103, 500-508.

Hills, B. P. (1992). The proton exchange cross-relaxation model of water relaxation in biopolymer systems. Mol. Phys. 76, 489-508.

Hills, B. P., Takacs, S. F. \& Belton, P.S. (1989). The effects of proteins on the proton NMR transverse relaxation times of water. I. Native bovine serum albumin. Mol. Phys. 67, 903-918.

Housset, D., Kim, K.-S., Fuchs, J., Woodward, C. \& Wlodawer, A. (1991). Crystal structure of a Y35G mutant of bovine pancreatic trypsin inhibitor. J. Mol. Biol. 220, 757-770.

Kimmich, R., Gneiting, T., Kotitschke, K. \& Schnur, G. (1990). Fluctuations, exchange processes, and water diffusion in aqueous protein systems. A study of bovine serum albumin by diverse NMR techniques. Biophys. J. 58, 1183-1197.

Koenig, S. H. (1980). The dynamics of water-protein interactions. Results from measurements of nuclear magnetic relaxation dispersion. In Water in Polymers (Rowland, S. P., ed.), ACS Symp. Series, vol. 127, pp. 157-176, Amer. Chem. Soc., Washington, DC.

Koenig, S. H. \& Brown, R. D. (1991). Field-cycling relaxometry of protein solutions and tissue: implications for MRI. Progr. NMR Spectrosc. 22, 487-567.

Koenig, S. H., Hallenga, K. \& Shporer, M. (1975). Protein-water interaction studied by solvent ${ }^{1} \mathrm{H},{ }^{2} \mathrm{H}$, and ${ }^{17} \mathrm{O}$ magnetic relaxation. Proc. Nat. Acad. Sci., U.S.A. 72, 2667-2671.

Koenig, S. H., Bryant, R. G., Hallenga, K. \& Jacob, G. S. (1978). Magnetic cross-relaxation among protons in protein solutions. Biochemistry, 17, 4348-4358.

Koenig, S. H., Brown, R. D. \& Ugolini, R. (1993). A unified view of relaxation in protein solutions and tissue, including hydration and magnetization transfer. Magn. Reson. Med. 29, 77-83.

Kossiakoff, A. A. (1985). The application of neutron crystallography to the study of dynamic and hydration properties of proteins. Annu. Rev. Biochem. 54, 1195-1227.

Kuhn, L. A., Siani, M. A., Pique, M. E., Fisher, C. L., Getzoff, E. D. \& Tainer, J. A. (1992). The interdependence of protein surface topography and bound water molecules revealed by surface accessibility and fractal density measures. J. Mol. Biol. 228, 13-22.

Kuhs, W. F. \& Lehmann, M. S. (1983). The structure of ice Ih by neutron diffraction. J. Phys. Chem. 87, 4312-4313.

Kuntz, I. D. \& Kauzmann, W. (1974). Hydration of proteins and polypeptides. Advan. Protein Chem. 28, 239-345.

Larsson, K., Tegenfeldt, J. \& Hermansson, K. (1991). Reorientation of water molecules in solid hydrates. Correlation with spectroscopic and structural data. I. Chem. Soc. Faraday Trans. 87, 1193-1200.

Levitt, M. (1983). Molecular dynamics of native protein. II. Analysis and nature of motion. J. Mol. Biol. 168, 621-657.

Levitt, M. \& Sharon, R. (1988). Accurate simulation of protein dynamics in solution. Proc. Nat. Acad. Sci., U.S.A. 95, 7557-7561. 
Lipari, G. \& Szabo, A. (1982). Model-free approach to the interpretation of nuclear magnetic resonance relaxation in macromolecules. 1. Theory and range of validity. J. Amer. Chem. Soc. 104, 4546-4559.

Meiboom, S. (1961). Nuclear magnetic resonance study of the proton transfer in water. J. Chem. Phys. 34, 375-388.

Meyer, E. (1992). Internal water molecules and H-bonding in biological macromolecules: a review of structural features with functional implications. Protein Sci. 1, 1543-1562.

Miura, N., Asaka, N., Shinyashiki, N. \& Mashimo, S. (1994). Microwave dielectric study on bound water of globule proteins in aqueous solution. Biopolymers, 34, 357-364.

Otting, G. \& Wüthrich, K. (1989). Studies of protein hydration in aqueous solution by direct NMR observation of individual protein-bound water molecules. J. Amer. Chem. Soc. 111, 1871-1875.

Otting, G., Liepinsh, E. \& Wüthrich, K. (1991a). Protein hydration in aqueous solution. Science, 254, 974-980.

Otting, G., Liepinsh, E. \& Wüthrich, K. (1991b). Proton exchange with internal water molecules in the protein BPTI in aqueous solution. J. Amer. Chem. Soc. 113, 4363-4364.

Pethig, R. (1992). Protein-water interactions determined by dielectric methods. Annu. Rev. Phys. Chem. 43, 177-205.

Piculell, L. \& Halle, B. (1986). Water spin relaxation in colloidal systems. Part $2 .{ }^{17} \mathrm{O}$ and ${ }^{2} \mathrm{H}$ relaxation in protein solutions. J. Chem. Soc. Faraday Trans. 1, 82, 401-414.

Poplett, I. J. F. (1982). ${ }^{1} \mathrm{H} /{ }^{2} \mathrm{H}$ and ${ }^{1} \mathrm{H} /{ }^{17} \mathrm{O}$ nuclear quadrupole double-resonance study of several hydroxide compounds. II. The water molecule. J. Magn. Reson. 50, 397-408.

Rashin, A. A., Iofin, M. \& Honig, B. (1986). Internal cavities and buried waters in globular proteins. Biochemistry, 25, 3619-3625.

Richarz, R., Nagayama, K. \& Wüthrich, K . (1980). Carbon-13 nuclear magnetic resonance relaxation studies of internal mobility of the polypeptide chain in basic pancreatic trypsin inhibitor and a selectively reduced analogue. Biochemistry, 19, 5189-5196.

Rupley, J. A. \& Careri, G. (1991). Protein hydration and function. Advan. Protein. Chem. 41, 38-173.

Saenger, W. (1987). Structure and dynamics of water surrounding biomolecules. Annu. Rev. Biophys. Biophys. Chem. 16, 93-114.

Schauer, G., Kimmich, R. \& Nusser, W. (1988). Deuteron field-cycling relaxation spectroscopy and translational water diffusion in protein hydration shells. Biophys. J. 53, 397-404.

Schneider, D. M., Dellwo, M. J. \& Wand, A. J. (1992). Fast internal main-chain dynamics of human ubiquitin. Biochemistry, 31, 3645-3652.

Smith, P.E. \& van Gunsteren, W. F. (1994). Translational and rotational diffusion of proteins. J. Mol. Biol. 236, 629-636.

Spiess, H. W., Garrett, B. B., Sheline, R. K. \& Rabideau, S. W. (1969). Oxygen-17 quadrupole coupling parameters for water in its various phases. J. Chem. Phys. 51, 1201-1205.

Sreenivasan, U. \& Axelsen, P. H. (1992). Buried water in homologous serine proteases. Biochemistry, 31, 1278512791.

Struis, R. P.W. J., de Bleijser, J. \& Leyte, J. C. (1987). Dynamic behavior and some of the molecular properties of water molecules in pure water and in $\mathrm{MgCl}_{2}$ solutions. J. Phys. Chem. 91, 1639-1645.

Szyperski, T., Luginbühl, P., Otting, G., Güntert, P. \& Wüthrich, K. (1993). Protein dynamics studied by rotating frame ${ }^{15} \mathrm{~N}$ spin relaxation times. J. Biomol. NMR, 3, 151-164.

Teeter, M. M. (1991). Water-protein interactions: theory and experiment. Annu. Rev. Biophys. Biophys. Chem. 20, 577-600.

Thanki, N., Thornton, J. M. \& Goodfellow, J. M. (1988). Distributions of water around amino acid residues in proteins. J. Mol. Biol. 202, 637-657.

Thanki, N., Umrania, Y., Thornton, J. M. \& Goodfellow, J. M. (1991). Analysis of protein main-chain solvation as a function of secondary structure. J. Mol. Biol. 221, 669-691.

Tüchsen, E., Hayes, J. M., Ramaprasad, S., Copie, V. \& Woodward, C. (1987). Solvent exchange of buried water and hydrogen exchange of peptide $\mathrm{NH}$ groups hydrogen bonded to buried waters in bovine pancreatic trypsin inhibitor. Biochemistry, 26, 5163-5172.

van der Maarel, J. R. C., Lankhorst, D., de Bleijser, J . \& Leyte, J. C. (1985). On the single-molecule dynamics of water from proton, deuterium and oxygen-17 nuclear magnetic relaxation. Chem. Phys. Letters, 122, 541-544.

van Gunsteren, W. F. \& Mark, A. E. (1992). On the interpretation of biochemical data by molecular dynamics computer simulation. Eur. J. Biochem. 204, 947-961.

Verhoeven, J., Dynamus, A. \& Bluyssen, H. (1969). Hyperfine structure of $\mathrm{HD}^{17} \mathrm{O}$ by beam-maser spectroscopy. J. Chem. Phys. 50, 3330-3338.

Vijay-Kumar, S., Bugg, C. E. \& Cook, W. J. (1987). Structure of ubiquitin refined at 1.8 Å resolution. J. Mol. Biol. 194, 531-544.

Wagner, G. (1983). Characterization of the distribution of internal motions in the basic pancreatic trypsin inhibitor using a large number of internal NMR probes. Quart. Rev. Biophys. 16, 1-57.

Wagner, G. (1993). NMR relaxation and protein mobility. Curr. Opin. Struct. Biol. 3, 748-754.

Wittebort, R. J., Usha, M. G., Ruben, D. J., Wemmer, D. E. \& Pines, A. (1988). Observation of molecular reorientation in ice by proton and deuterium magnetic resonance. J. Amer. Chem. Soc. 110, 5668-5671.

Wlodawer, A., Walter, J., Huber, R. \& Sjölin, L. (1984). Structure of bovine pancreatic trypsin inhibitor. Results of joint neutron and X-ray refinement of crystal form II. J. Mol. Biol. 180, 301-329.

Wlodawer, A., Deisenhofer, J. \& Huber, R. (1987a). Comparison of two highly refined structures of bovine pancreatic trypsin inhibitor. J. Mol. Biol. 193, 145-156.

Wlodawer, A., Nachman, J., Gilliland, G. L., Gallagher, W. \& Woodward, C. (1987b). Structure of form III crystals of bovine pancreatic trypsin inhibitor. J. Mol. Biol. 198, 469-480.

Woessner, D. E. (1962). Nuclear spin relaxation in ellipsoids undergoing rotational brownian motion. J. Chem. Phys. 37, 647-654.

Xu, R. X., Meadows, R. P. \& Fesik, S. W. (1993). Heteronuclear 3D NMR studies of water bound to an FK506 binding protein/immunosuppressant complex. Biochemistry, 32, 2473-2480.

Edited by R. Huber 